\title{
Chitosan Based Membranes for Separation, Pervaporation and Fuel Cell Applications: Recent Developments
}

\author{
Tina Chakrabarty, Mahendra Kumar and Vinod K. Shahi \\ Electro-Membrane Processes Division, \\ Central Salt and Marine Chemicals Research Institute, Council of Scientific \& Industrial \\ Research (CSIR), G. B. Marg, Bhavnagar-364002 (Gujarat)
}

India

\section{Introduction}

Growing public health and environmental awareness accompanied by increasing number of stricter environmental regulations on wastes discharge. Attention has been focused on the use of biopolymers from renewable resources as alternatives to synthetic polymers [1]. Biopolymers are produced in nature by living organisms and plants, participate in the natural biocycle and are eventually degraded and reabsorbed in nature. The most widespread biopolymers are polysaccharides among them chitosan(CS) is most valuable, whose swellability in water and viscous solution/gel-forming properties were utilized by manufacture for number of industrial and consumer products. CS (primary derivative of chitin) is commercially available basic polysaccharide [2,3]. The basicity of CS responsible for singular chemical and biological characteristics, biocompatibility, antibacterial properties, heavy metal ion chelation ability, gel-forming properties, hydrophilicity, affinity to proteins and good membrane forming capability. In this chapter we will discuss for modification of CS and its exploitation for advance membrane separation applications. The membrane processes were classified by Howell includes [4]:

1. Cleaner industrial process: adsorption, ultrafiltration and electro-ultrafiltration.

2. Energy: fuel cell applications

3. Pervaporation: separation of organic solvents from their azeotropic mixtures.

4. Water: virus-free supply, water reuse and micro-pollutant-free water

Chitosan is obtained by varied extent $N$-deacetylation and characterized by degree of deacetylation (Fig. 1). It is a copolymer of $\mathrm{N}$-acetyl glucosamine and glucosamine and insoluble in water. CS readily dissolves in acidic solutions due to the presence of amino groups and $80-85 \%$ degree of deacetylation is necessary to obtain a soluble product. Commercially, CS is obtained from low cost shells of shellfish (mainly crabs, shrimps, lobsters and krills), the wastes of the seafood processing industry [2-6]. Chemical and biological properties of CS attributable to the presence of amino and hydroxyl groups [2,3,58]. These groups allow chemical modifications of chitosan: acylation, $N$-phthaloylation, tosylation, alkylation, Schiff base formation, reductive alkylation, $\mathrm{O}$-carboxymethylation, $\mathrm{N}$ carboxyalkylation, silylation, and graft copolymerization [3,9]. Modifications of CS will help 
for tailor-made materials of specific applications such as adsorption, polymer electrolyte membrane (PEM) for the separation of metal ions, amino acids and protein by adsorption, ultrafiltration, electro-ultrafiltration, fuel cell application and pervaporation. Additionally, amino groups made CS a cationic polyelectrolyte $\left(\mathrm{p} K_{\mathrm{a}} \approx 6.5\right)$, due to its solubility in aqueous acidic media at $\mathrm{pH}<6.5$. When dissolved, CS possesses a high positive charge on $-\mathrm{NH}_{3}{ }^{+}$ groups and makes aggregates with polyanionic compounds, and chelates with heavy metal ions. CS has drawn particular attention as effective biosorbent, due to its low cost compared to activated carbon and its high amino and hydroxyl functional group contents responsible for high adsorption potential for various aquatic pollutants [9-14]. This biopolymer represents an attractive alternative over other biomaterials because of its physico-chemical characteristics, chemical stability, high reactivity, excellent chelation behavior and high selectivity toward pollutants [15-16]. Natural chitosan was modified by several methods (either physically or chemically) to enhance the adsorption capacity for various types of pollutants. Different shapes of chitosan, e.g. membranes, microspheres, gel beads and films have been prepared and examined for the removal of various pollutants from water and wastewater. CS has been employed as a promising polymeric matrix for DMFC application considering its low cost, desirable alcohol barrier property and proton conductivity as well as adequate thermal stability after cross-linking [17-19]. Reports are available, where chitosan has been used as membrane forming material in pervaporation for the dehydration of alcohols, because of its hydrophilic nature and very high affinity towards water [20-22].

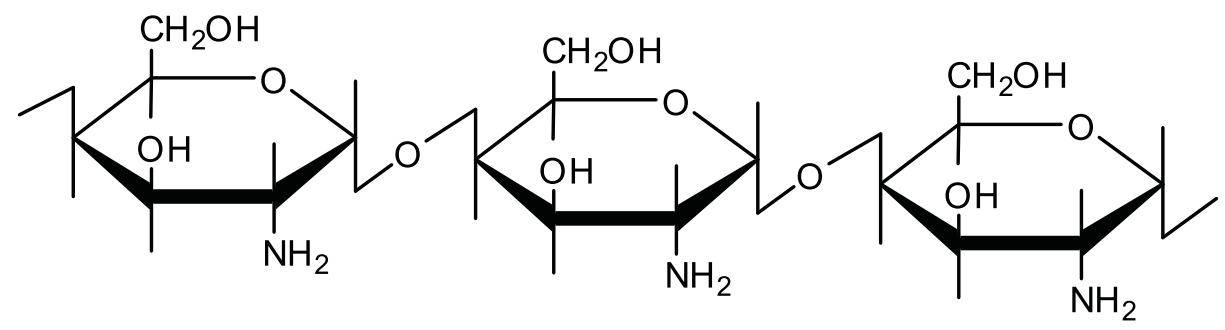

Fig. 1. Chemical structure of Chitosan.

\section{Adsorption}

Water is one of the basic necessities required for the sustenance and continuation of life. It is therefore important to supply good quality of water for various activities. However, this is becoming increasingly difficult in view of large scale pollution caused by industrial, agricultural and domestic activities. These activities generate wastewater which contains both inorganic and organic pollutants. Some of the common pollutants are phenols, dyes, detergents, insecticides, pesticides and heavy metals [23,24].

\subsection{Chitosan based adsorbents for the separation and recovery of pollutants from wastewater}

During recent years, CS derivatives were successfully utilized for removal of anions from wastewater. The adsorption of nitrate by CS hydrobeads was examined by Chatterjee and Woo [25]. Desorption of nitrate from the loaded beads was accomplished by increasing the $\mathrm{pH}$ of the solution to the alkaline range, and $87 \%$ desorption ratio of nitrate was achieved at $\mathrm{pH}$ 12.0. The applicability of neodymium-modified chitosan as adsorbents for removal of 
excess fluoride ions was studied by Yao et al [26]. Three cross-linked CS derivatives were used for the removal of $\mathrm{Cr}(\mathrm{VI})$ from aqueous solutions: (i) CS, without grafting; (ii) CS grafted with acrylamide (CS-g-Aam) and (iii) CS grafted with acrylic acid ( CS-g-Aa). CS-gAam exhibited the highest sorption capacity for $\mathrm{Cr}(\mathrm{VI})$ removal $\left(935 \mathrm{mg} \mathrm{g}^{-1}\right)$ at $\mathrm{pH}: 4.0$ [27].

The metal-binding property of chitosan was used to incorporate titanium (Ti) metal and applied as an adsorbent for fluoride adsorption by Ti loading. It was observed that an increase in titanium loading from 5 to 15\% improved fluoride removal from 61 to 89\% [28]. CS intercalated montmorillonite (CS-MMT) was prepared by dispersing sodium montmorillonite (Na+-MMT) into CS solution at $60{ }^{\circ} \mathrm{C}$ for $24 \mathrm{~h}$. CS-MMT showed the highest $46-49 \mathrm{mg}$ gladsorption capacity, which was attributed to the existence of intercalate-CS, and enlarged its pore structure and facilitated the penetration of macromolecular dyes bound electro-statically [29]. N-benzyl mono- and disulfonate derivatives of CS were also used for the removal of dyes in aqueous media. Results confirmed the strong cation exchange character of the sulfonated derivatives with $121.9 \mathrm{mg} \mathrm{g}^{-1}$ adsorption capacity at $\mathrm{pH}$ : 3.0 [30]. Four kinds of phenol derivatives: 4-hydroxybenzoic acid (BA), 3,4-dihydroxybenzoic acid (DBA), 3,4dihydroxyphenyl-acetic acid (PA), and hydrocaffeic acid (CA), were grafted onto CS substrate, individually. The modified CS derivatives were used for removal of cationic dyes (crystal violet $(\mathrm{CV})$ and bismarck brown $\mathrm{Y}(\mathrm{BB})$ ). The optimum adsorptive uptake for $\mathrm{CV}$ and $\mathrm{BB}$ occurred at $\mathrm{pH}: 7.0$ and 9.0 at $30^{\circ} \mathrm{C}$, respectively [31].

Simultaneous removal of various metal ions (zinc, copper, cadmium, and lead) in aqueous media was achieved by commercially available CS flakes [32]. Cross-linked CS gel beads were also used for molybdate sorption. Authors reported $700 \mathrm{mg} \mathrm{g}^{-1}$ adsorption capacity in batch studies [33]. Cross-linking of CS particles with glutaraldehyde, epichlorhydrine, or EGDE (ethylene glycol glycidyl ether) enhanced the resistance of sorbent beads against acids, alkali or chemicals [34]. Contamination of natural waters by arsenic in is a worldwide problem, which is a health hazard. Extensive research has been conducted to control/minimize the arsenic contamination in drinking water. Sorption of $\mathrm{As}(\mathrm{V})$ on molybdate impregnated CS gel beads was investigated [35]. CS derivatives were also found to be efficient for removing gold from dilute acidic solutions, with $600 \mathrm{mg} \mathrm{g}^{-1}(3 \mathrm{mmol} \mathrm{g}-1)$ uptake capacity. However, $102 \mathrm{mg} \mathrm{g}^{-1}$ adsorption capacity was recorded as high as for 100 $\mathrm{mgl}^{-1}$ initial $\mathrm{Cr}(\mathrm{VI})$ concentration. Results showed that both monolayer adsorption and intraparticle diffusion mechanisms limited the rate of $\mathrm{Cr}(\mathrm{VI})$ adsorption [36]. Quaternary ammonium salt of chitosan (QCS) was synthesized via reaction of a quaternary $\backslash$ trimethyl ammonium, glycidyl chloride and examined for $\mathrm{Cr}(\mathrm{VI})$ removal [37]. Cross-linked CS/PVA beads with low water content were prepared by suspension of aqueous solution of chitosan/PVA in toluene-chlorobenzene medium using glutaraldehyde as cross-linking agent in acidic conditions [38]. The developed beads exhibited quite low degree of swelling of prepared beads due to water loving nature of beads and considerable hydrogen bonding with hydrophilic groups. Both nitrogen and oxygen atom posses lone pair of electrons, can bind a positively charged ion through the electron pair sharing. The easy release of lone pair from nitrogen atom makes it the main binding site and forms stable metal complex. With the above consideration, the following chemical reactions are proposed to account the mechanism of $\mathrm{Cd}(\mathrm{II})$ adsorption and desorption:

$$
\begin{gathered}
\mathrm{R}-\mathrm{NH}_{2}+\mathrm{H}^{+} \rightarrow \mathrm{R}-\mathrm{NH}_{3}^{+} \\
\mathrm{R}-\mathrm{NH}_{2}+\mathrm{Cd}^{2+} \rightarrow \mathrm{R}-\mathrm{NH} 2 \mathrm{Cd}^{2+}
\end{gathered}
$$




$$
\begin{gathered}
\mathrm{R}-\mathrm{NH}_{3}^{+}+\mathrm{Cd}^{2+} \rightarrow \mathrm{R}-\mathrm{NH} 2 \mathrm{Cd}^{2+}+\mathrm{H}^{+} \\
\mathrm{R}_{-} \mathrm{NH}_{2}^{+} \mathrm{Cd}^{2+}+\mathrm{H}_{2} \mathrm{O} \rightarrow \mathrm{CdOH}^{+}+\mathrm{R}_{-} \mathrm{NH}_{3}^{+}
\end{gathered}
$$

The maximum adsorption capacity of $\mathrm{Cd}(\mathrm{II})$ on chitosan-coated perlite beads at $\mathrm{pH}$ : 6 was found to be 78 and $178.6 \mathrm{mg} \mathrm{g}^{-1}$ of beads from a solution containing 1000 and $5000 \mathrm{mg} \mathrm{l}^{-1}$ of $\mathrm{Cd}(\mathrm{II})$, respectively, at $298 \mathrm{~K}$. Breakthrough data from a column were used to calculate the diffusion coefficients for $\mathrm{Cd}(\mathrm{II})$ into the chitosan coated perlite beads, and the diffusion coefficient was found to be $8 \times 10^{-13} \mathrm{~m}^{2} \mathrm{~s}-1$ [39]. The modification of $-\mathrm{OH}$ groups on CS chemical reactions using ehtylenediamine and carbodiimide (CR) were also studied [40]. $\mathrm{Hg}$ (II) uptake by CS cross-linked with gluteraldehyde (GLA) and (CR) subsequently treated with EPI (CR-Cl) followed by reaction with ethylene diamine (CR-amine) or 3-amino-1,2,4thiazole-5 thiol (CR-azole) was studied [41]. $\mathrm{Hg}$ (II) adsorption behavior of cross-linked carboxymethyl chitosan was reported with $124.4 \mathrm{mg} \mathrm{g}^{-1}$ maximum adsorption capacity (pH: 5.0) [42]. Donia et al. modified magnetic chitosan by use of a Schiff's base cross-linker (GLA+thiourea) and studied the removal of $\mathrm{Hg}(\mathrm{II})$ solutions by the obtained resin [43]. Observed adsorption capacity was attributed to the presence of the free lone pair of electrons on $\mathrm{N}$ and $\mathrm{S}$ atoms suitable for coordination with soft acid i.e. $\mathrm{Hg}$ (II) ions. Novel CS based chelating resin (CCTS-TAA) was also synthesized for $\mathrm{Hg}$ (II) adsorption from EDGEcross-linked chitosan (CCTS) followed by chemical modification with tris(2aminoethyl)amine (TAA) moiety The CCTS-TAA resin possesses tertiary and primary amine groups, presenting the tertiary amine higher affinity and selectivity for $\mathrm{Hg}$ (II) [44]. Gen et al. reported the use of Procion Brown MX 5BR immobilized poly(hydroxyethylmethacrylate/CS) composite membrane (pHEMA/CS) for removal of $\mathrm{Hg}$ (II) from aquatic systems.

The CS and N-carboxymethyl CS (NCMCS) beads were used as an adsorbent for the gold (III) $\left(\mathrm{Au}^{3+}\right)$ removal from wastewater. Adsorption of $\mathrm{Au}^{3+}$ ions occurred only at the optimum $\mathrm{pH}$ and kinetic studies showed a rapid adsorption of $\mathrm{Au}^{3+}$ from aqueous solution. The experimental data of the adsorption equilibrium from $\mathrm{Au}^{3+}$ solutions correlated well with the Langmuir adsorption isotherm. The maximum desorption of $\mathrm{Au}^{3+}$ was obtained from CS/ NCMCS beads by the treatment with EDTA solution of known concentration. The $\mathrm{Au}^{3+}$ ions can be easily removed from CS or NCMCS by treatment with an aqueous EDTA solution, therefore making it possible to collect the $\mathrm{Au}^{3+}$ ions and recycle the CS and NCMCS beads [45]. The adsorption of $\mathrm{Al}(\mathrm{III})$ from aqueous solutions onto CS was studied in a batch system [46]. The cross-linked N,O-carboxymethyl- CS resin with $\mathrm{Pb}(\mathrm{II})$ as template ions (cross-linked CMCS template) were synthesized and cross-linked with glutaraldehyde to improve adsorption selectivity for heavy metals. The adsorption experiments demonstrated high adsorption selectivity for $\mathrm{Pb}$ (II) of cross-linked CMCS template. Furthermore, although the adsorption capacities for $\mathrm{Cu}(\mathrm{II}), \mathrm{Co}(\mathrm{II}), \mathrm{Ni}(\mathrm{II}), \mathrm{Zn}$ (II) decreased in compare with CMCS for adsorption of $\mathrm{Pb}(\mathrm{II})$ from the mixture solution of $\mathrm{Pb}(\mathrm{II})-\mathrm{Cu}(\mathrm{II})-\mathrm{Zn}$ (II) solutions. This was an effective way to separate $\mathrm{Cu}(\mathrm{II}), \mathrm{Zn}$ (II) and $\mathrm{Pb}$ (II) ions selectively. The sorption of $\mathrm{CMC}$ and the cross-linked $\mathrm{CMC}$ template for $\mathrm{Pb}(\mathrm{II})$ was a chelate process through both oxygen and nitrogen atoms co-ordinated with $\mathrm{Pb}(\mathrm{II})$ in the polymer chain [47] The PAAc-functionalized chitosan granules (CS-PAAc) showed significantly greater adsorption capacities for lead ions than CTS, and the performance improved with the increase of $\mathrm{pH}$ : 1-6. The excellent adsorption performance of CS-PAAc for $\mathrm{Pb}^{2+}$ was attributed to the many carboxyl groups grafted on CS-PAAc beads. Desorption study showed regeneration of adsorbent without 
any loss of adsorption capacity and confirmed utilization of CTS-PAAc to remove $\mathrm{Pb}^{2+}$ ions from the wastewater [48].

ions from aqueous solution. The amount of adsorbed $\mathrm{Cu}^{2+}$ per gram of the beads decreased with the increase of $\mathrm{CS}$ and $\mathrm{NaOH}$ concentration in the beads [49]. CS was chemically modified with 2[-bis(pyridylmethyl)aminomethyl]-4-methyl-6-formylphenol (BPMAMF) and employed to study the kinetics and the equilibrium adsorption of $\mathrm{Cu}(\mathrm{II}), \mathrm{Cd}(\mathrm{II})$, and $\mathrm{Ni}$ (II) metal ions as functions of the solution $\mathrm{pH}$ [50]. The kinetics was evaluated for the utilization for the pseudo-first-order and pseudo-second-order equation models and the equilibrium data were analyzed by Langmuir and Freundlich isotherms models. The adsorption kinetics follows the mechanism of the pseudo-second-order equation for all studied systems and this mechanism suggests that the adsorption rate of metal ions by CHS-BPMAMF dependent on the number of ions on the adsorbent surface, as well as on their number at equilibrium. Modified CS, 2[-bis-(pyridylmethyl) aminomethyl]-4-methyl-6formyl-phenol (HL by Schiff's base reaction), was identified as new adsorbent materials for the removal of $\mathrm{Cu}(\mathrm{II})$ in aqueous media [51].

\subsection{Chitosan based membranes for the adsorption/separation of amino acids and proteins}

Introduction of silica into the CS created a dense and uniform hybrid network and reduced the degree of swelling of the materials in aqueous system, which ensured the formation and maintenance of imprinting sites. The specific interactions of imprinting cavities in the hybrid membrane with templates resulted in a significantly improved chiral resolution of the imprinted membranes by strengthening the binding ability of the imprinting molecules, hindering their diffusion and facilitating the transport of the other isomers. The chiral separation ability of CS/ glycidyl propyl trimethoxysilane (GPTMS) hybrid molecularly imprinted membranes towards the underivatized d,l-Phe aqueous mixture was evaluated by permeation and binding experiments. The selectivity of the developed membrane was increased along with a 4.5 separation factor [51,52]. Porous structured CS- $\beta$-cyclodextrin (CD) membranes were synthesized by incorporating $\beta-C D$ polymers as the functional moiety and GPTMS used as cross-linking agent [53]. The developed membrane exhibited the significant changes in molecular constitutions, crystalline and thermal properties.

Modifications of CS were carried out by either introducing phosphonic acid group or by quaternization of existing primary amine groups in order to make it water soluble [54]. The functionalized materials were used to prepare charged nanoporous composite membranes of different compositions of $N$-methylene phosphonic chitosan (NMPC) and quaternized chitosan (QC) by taking required modified materials and poly(vinyl alcohol) $50 \%(\mathrm{w} / \mathrm{w})$ in aqueous media and later the membranes were gelated in methanol at $10^{\circ} \mathrm{C}$ to tailor pore structure in the membrane matrix. FTIR and IEC studies confirmed the introduction of phosphonic acid groups and quaternary ammonium groups, resulting in formation of crosslinking or covalent bonding with PVA that resulted the composite membranes. Thermodynamic properties of dilute aqueous solutions of NMPC, QC, and their mixture were also studied and it was concluded that both individual materials have good hydrophilic interactions with water and mixed solution exhibited electrostatic interactions between negatively charged $-\mathrm{PO} 3 \mathrm{H} 2$ and positively charged $-\mathrm{N}+(\mathrm{CH} 3) 3$ groups. Membrane conductivity studies revealed that $\mathrm{PC} / \mathrm{QC}-30$ was a relatively dense membrane and may be able to discriminate between different types of ions based on their ionic radii. The values of 
diffusion coefficient of ions across the membranes $\left(\mathrm{Dm}^{i}\right)$ for different electrolytes follow the trend $\mathrm{NaCl}>\mathrm{CaCl} 2>\mathrm{MgCl} 2$ in the case of PC/QC-30 membrane which suggested the applicability of the developed membrane for the electrolyte separations, because of their varied diffusional migration. Membrane permeation studies also confirmed the lowest equivalent pore radius for PC/QC-30 membrane, and the relative permeability of these membranes for different types of ions suggests the suitability of PC/QC-30 membrane for the separation of $\mathrm{Na}+$ from $\mathrm{Ca} 2+$ and $\mathrm{Mg} 2+$ mixture.

Cross-linked CS/ poly(methacrylic acid) (PMAA) particles was obtained via template polymerization. The resultant particles were characterized for different charge density regions. Albumin was adsorbed on these particles (after cross-linking with glutaraldehyde), and $\mathrm{pH}$ was controlled for: (i) adsorption of positively charged albumin and (ii) adsorption of albumin at its iso-electric point. Adsorption isotherms and zeta potential ( $\zeta$ ) measurements showed that albumin adsorption was controlled by hydrogen bonding/van der Waals interactions and the brush-like structures may enhance the adsorption of albumin on these particles. It was also found that shearing can induce desorption of albumin from PEC surface, depending on the continuous phase albumin concentration [55]. Semiinterpenetrating networks (IPN)-structured CS/ $\beta$-cyclodextrin (CS/CD) composite membranes were prepared and used for the enantiomeric separation of tryptophan (Trp) racemate mixture. The diffusion selectivity as compared to sorption selectivity was responsible for the enantiomeric separation of Trp. Thus the overall sorption-diffusion process could be condensed to a mechanism which is schematically illustrated in Fig. 2. Both CS and $\beta$-CDP exhibited 1-Trp selectivity in the sorption process, and the concentration gradient built by sorption process between donor side and receptor side within membrane thickness contributed to the following diffusion process. The diffusion process was predominant for the fact that the sorption process showed a 1-Trp selectivity while the overall sorption-diffusion process favored d-Trp. Due to lower complexation selectivity of $\beta$-CDP which narrow the difference between diffusion resistances of $d$ and l-Trp, the

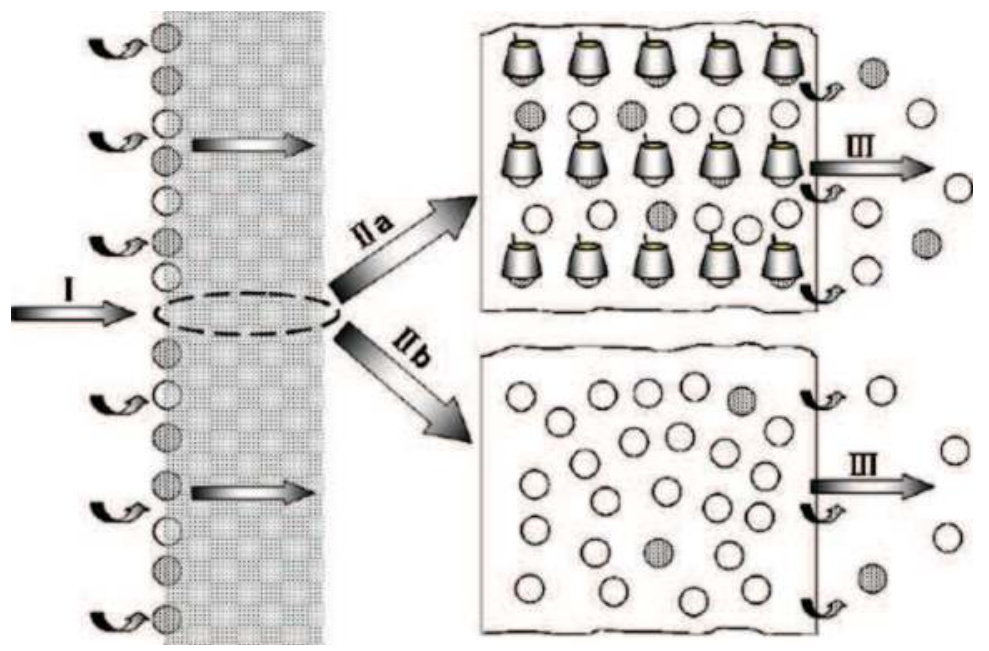

Fig. 2. Schematic illustration of the overall solution-diffusion process within CS/CD membrane. 
diffusion rate difference between $\mathrm{d}$ - and 1-Trp diminished that accounts for a decreased permselectivity in the presence of $\beta$-CDP. Meanwhile, permeate flux for both $d$ - and 1-Trp was found to increase considerably with the increase of $\beta$-CDP content within the membrane, which could be attributable to the facilitated mass transport of Trp enantiomers through $\beta$-CDP within the membrane. Both CS and $\beta$ CDP exhibited l-sorption selectivity in the sorption experiment, and while the complexation selectivity of $\beta$-CDP with Trp was relatively lower, which would reduce. The obtained results provided useful information for the development of composite membranes for enantiomers separations [56].The surface of CS films was modified to introduce the positive and negative charges. The positively charged CS surface was prepared by a reaction between the amine group of CS and methyl iodide $\left(\mathrm{CH}_{3} \mathrm{I}\right)$ to form the quaternary ammonium-functionalized CS surface (QAC film) as depicted in Scheme 1[57].
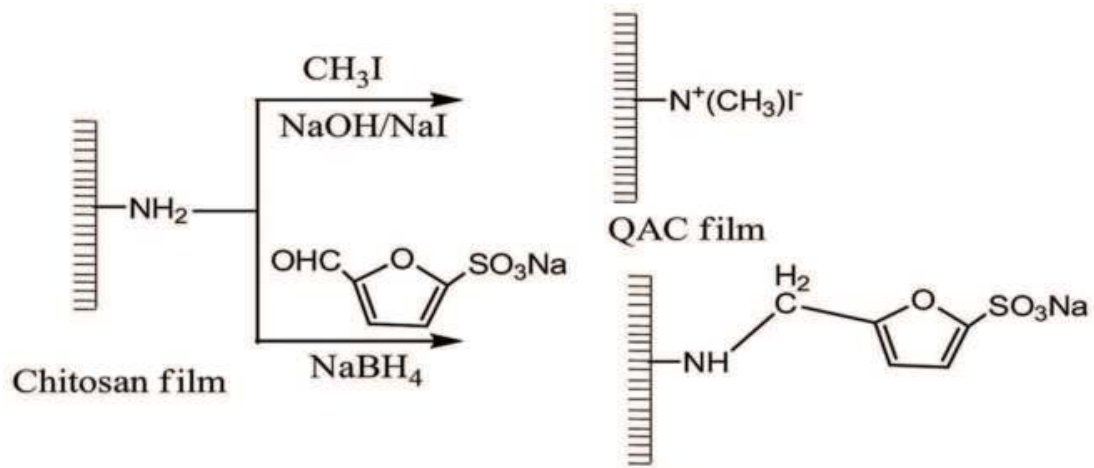

\section{SFC film}

Scheme 1. Introduction of charged fuctional groups to the surface of chitosan.

The CS/CMC blend membranes were prepared by a simple solution-blending method with glutaraldehyde as a cross-linking agent for CS and with silica particles as progens [58]. Shi et al. oworkers developed affinity membranes by immobilizing $\mathrm{Cu}^{2+}$ ions onto $\mathrm{CS}$ modified disc alumina to purify hemoglobin from a hemolysate and achieved a binding capacity of $\sim 17.5 \mathrm{mg}$ of hemoglobin per gram of membrane [59]. CS-Cibacron blue F3GA affinity membranes were prepared in three steps: (i) dissolving CS in a dilute acetic acid solution; (ii) pouring the CS solution containing PEG as progen over a microporous polyether sulfone (PES) membrane; and (iii) coupling the membrane with the dye under the mild alkaline condition [60]. Adsorption studies of human serum albumin (HSA) on developed substrate under the equilibrium and dynamic conditions revealed as affinity membrane having the good adsorption capacity for HAS. The surface of CS films modified with amine groups of the glucosamine units affected the hydrophobicity. The improved surface hydrophobicity affected by the stearoyl groups promoted protein adsorption. In contrast, selective adsorption behavior was observed in the case of CS films modified with anhydride derivatives. Lysozyme adsorption was enhanced by $\mathrm{H}$-bonding and charge attraction with the hydrophilic surface. While the amount of albumin adsorbed was decreased possibly due to negative charges that gave rise to repulsion between the modified surface of CS and albumin [61]. The adsorption of human IgG on the immobilized protein on a composite membrane was further studied under both equilibrium and dynamic conditions. The 
equilibrium adsorption did not follow the Langmuir model, but well fitted the FreundlichLangmuir adsorption isotherms. The results indicated that the affinity of CS/cellulose membrane has a great potential in fast purification of biomolecules [62]. The concept of chiral ligand exchange was employed to achieve the chiral resolution of tryptophan (Trp) enantiomers by using CS membrane in a sorption resolution mode and $\mathrm{Cu}$ (II) ion acted as the complexing ion. Porous CS membranes were prepared by freeze-drying method (CS-LT) and sol-gel process at high temperature (CS-HT), respectively, to investigate their sorption resolution characteristics. The CS chiral ligand exchange membranes exhibited good chiral resolution capability. Meanwhile the sorption selectivity of the CS membranes was found to be reversed from L-selectivity at low $\mathrm{Cu}$ (II) ion concentration to D-selectivity at high copper(II) ion concentration, which was attributable to the stability difference between the copper(II)-L-Trp and Cu(II)-D-Trp complexes. Moreover, CS-HT membrane showed better performance with respect to both sorption selectivity and sorption capability than CS-LT membrane, which mainly resulted from its more amorphous structures as compared with the more crystalline structures of CS-LT membrane. The superiority of sorption capability of CS-HT membrane is also attributable to its larger specific surface area than that of CS-LT membrane. The results obtained were conducive to the design and fabrication of chiral ligand exchange membranes for enantiomeric separation in sorption mode [63]. Affinity membranes based on a $\mathrm{Ni}^{2+}$-chelating CS surface were fabricated to immobilize C-terminus hexa histidine-tagged green fluorescent protein (His-GFP) [64]. The ability of histidinetagged proteins to chelate with $\mathrm{Ni}^{2+}$ ions that were coordinated to functionalized polymeric matrices. Both membranes had comparable amounts of his-GFP immobilized on the surface. However, the amount of anti GFP bound to the $\mathrm{Ni}^{2+}$-chelated his-GFP complex at saturation was higher than that bound to the glutaraldehyde-immobilized his-GFP by a factor of five. Furthermore, fitting the data to a single-site Langmuir model resulted in an affinity constant for the $\mathrm{Ni}^{2+}$ chelated his-GFP complex towards anti GFP was 14 times higher than the glutaraldehyde-immobilized his-GFP. The higher affinity suggested that immobilizing a protein at its C-terminus resulted in the proper orientation for subsequent binding of antibodies. At low antibodies concentrations, the sensitivity of the affinity membrane was 70 times than that of the control. The ability to capture specific proteins with their respective antibodies would be highly advantageous to any assay based on the identification of biomarker proteins. Beppu et al. [65] prepared CS membrane and cross-linked with glutaraldehyde in order to see the effect on ion permeability and water adsorption property. Heterogeneous cross-linking with glutaraldehyde showed to produce more CS structures in CS membranes, which then interfere in the interaction with water and ions and changes their mechanical characteristics. Thus the developed membrane can be easily used for the separation of cations from their mixture solution [66]. The permeability coefficients of the metal ions obeyed the models, those for CS membranes were found lower than predicted values and found the largest deviation than the transition metal ions. The diffusive properties of CS membranes towards metal ions offer potential for protection of CS based biological systems against destructive effects of heavy metal ions. A new kind of metal affinity membrane based on a ceramic support was prepared by: (i) deposition of a CS layer in order to functionalize the ceramic support; (ii) cross-linking with epichlorohydrin to stabilize the polymer layer and to enable for further grafting, and (iii) grafting of iminodiacetic acid [67]. Schematic structure of affinity membrane is presented in Fig. 3. Due to the ceramic support, this membrane is highly resistant and CS layer brings 


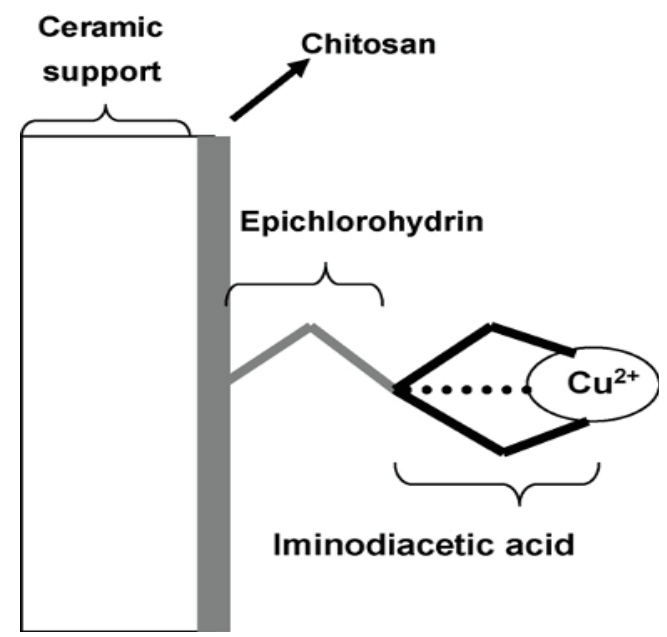

Fig. 3. Schematic representation of the affinity membrane.

biocompatibility properties. The commercially available membranes were modified with cationic layer of quaternized CS to enhance their selectivity towards the metal ions [68]. Highly porous CS/ cellulose acetate (CA) blend hollow fibers as adsorptive membranes were successfully fabricated through a wet spinning process with CA and CS. The developed hollow fiber based membranes can be efficiently used for affinity-based separations of metal ions, amino acids and proteins [69]. The hollow fiber membranes were prepared from CA acted as a matrix polymer and CS functional polymer to provide the membrane with coupling or active sites for affinity-based separations. Formic acid was used as the co-solvent for both CA and CS to prepare the dope solution and $\mathrm{NaOH}$ solution was used as the external and internal coagulants in the wet spinning fabrication process. The properties of the blend hollow fibers membranes were characterized through water flux measurements, surface and cross-section examinations. Adsorption performances of the composite membranes for $\mathrm{Cu}^{2+}$ ions and BSA on the surface were compared with CA hollow fibers membranes. The blend hollow fibers membranes achieved significantly better adsorption performance as compared to CA hollow fibers, indicating the benefit of adding CS into CA to make novel blend hollow fibers membranes in improving the performance of the traditional CA hollow fibers, especially for the affinity-based separations [70]. Compared to chromatographic methods, membrane separation techniques offer advantages of lower cost and ease to scale-up for commercial production. However, the lack of membrane selectivity and its fouling due to protein absorption during filtration has severely restricted their ultrafiltration (UF) applications [71]. Nowadays, UF has been widely used as preferred method for protein concentration and buffer exchange that replaced size exclusion chromatography in these applications [72]. UF membranes prepared from a variety of synthetic polymers have high thermal stability, chemical resistivity, and restricted the use of fairly harsh cleaning chemicals [73]. The choice of membrane was usually guided by its molecular weight cut-off (MWCO), which is defined as the equivalent molecular weight of the smallest protein that would exhibit above $90 \%$ rejection. However, the experimental conditions and systems used to evaluate $90 \%$ MWCO have not been standardized [74]. Fractionation of dairy wastewater into lactose-enriched and protein-enriched streams using 
UF membrane technique was also studied. Three regenerated cellulose membranes of 3, 5 and $10 \mathrm{kDa}$ MWCO were used to determine the process efficiency. The performance was determined under various processing conditions that include the operating temperature, trans-membrane pressure across the membranes and the concentration of lactose in the feed solution [75].

CS/polystyrenesulfonate (PSS) multilayers membrane on PES supports was prepared by casting method. The developed membrane was used in ultrafiltration for the separation of ternary mixture of proteins (BSA, ovalbumin and Lysozyme (LYS) mixture [76]. BSA was rejected by the multilayer membrane at all the studied concentrations $(0.25,0.5,1.0$ and 2.0 $\mathrm{mg} \mathrm{ml}^{-1}$ ). BSA solution flux was found to decrease with an increase in BSA concentration. BSA-lysozyme separation may also be achieved using the with multilayer composite charged ultrafilter membrane. Hydrophobic poly (vinylene diflouride) (PVDF) membrane was modified with CS in order to reduce the protein fouling in ultrafiltration. The hydrophilicity of the modified membrane increased (decline in contact angle) with increasing CS concentration and modification time. However, the water permeate flux was decreased with the increase in CS concentration and modification time. Moreover, the modification method significantly affected the deposition of CS on membrane surface and pore wall. The protein fouling study was carried out and found that the normalized flux during the BSA filtration slightly declined when modified membrane having the high CS concentration. The modification of PVDF membrane with CS could effectively prevent protein fouling on membrane. Protein adsorption on the modified membrane was highest at BSA iso-electric point (IEP) while the adsorption decreased at BSA solution $\mathrm{pH}$ was far from the IEP [77].

The fabrication of a novel composite membrane with high flux and good selectivity was carried out by modifying the surface of a microfiltration membrane with a uniform coating of CS/ PSS polyelectrolyte multilayer, which may find application in protein separations under ultrafiltration conditions. The individual transport studies of ovalbumin and lysozyme indicated that these egg white proteins could be separated using multilayer deposited charged ultrafilter membrane [78]. Experimental data collected includes total flux as a function of time, as well as final protein deposition dependant on feed volume flow, $\mathrm{pH}$ and protein concentration [79]. The Poly(acrylonitrile) (PAN)/CS composite ultrafiltration membranes were prepared by filtration of CS solution through PAN base membrane and subsequent curing and treatment with $\mathrm{NaOH}$. The formation of CS layer on the surface of PAN base membrane was confirmed by Fourier transformer infrared (FTIR), X-ray photoelectron spectroscopy (XPS) and scanning electron microscopy (SEM). While the deposition of CS on the pore walls was confirmed by determination of various parameters such as pure water permeation, pore size distribution and MWCO and it was found that decline in studied parameters compared with pristine membrane. The composite membranes were stable in aqueous medium and showed reduction in pure water fluxes after the filtration of aqueous acidic ( $\mathrm{pH}$ : 3.0) and basic $(\mathrm{pH}: 11.0)$ solution, which was attributed to the swelling of CS layer. The composite ultrafiltration membranes can be efficiently used for the separation of proteins from their mixture [80].

The use of electric field in UF goes back to the first study carried out by Bechhold by imposing electric field in UF and utilized a combination of electro-osmosis and electrophoresis to purify colloids in an apparatus he called an 'electro-ultrafiltration' (EUF) [81]. EUF is an effective method to decrease gel layer formation on the membrane surface 


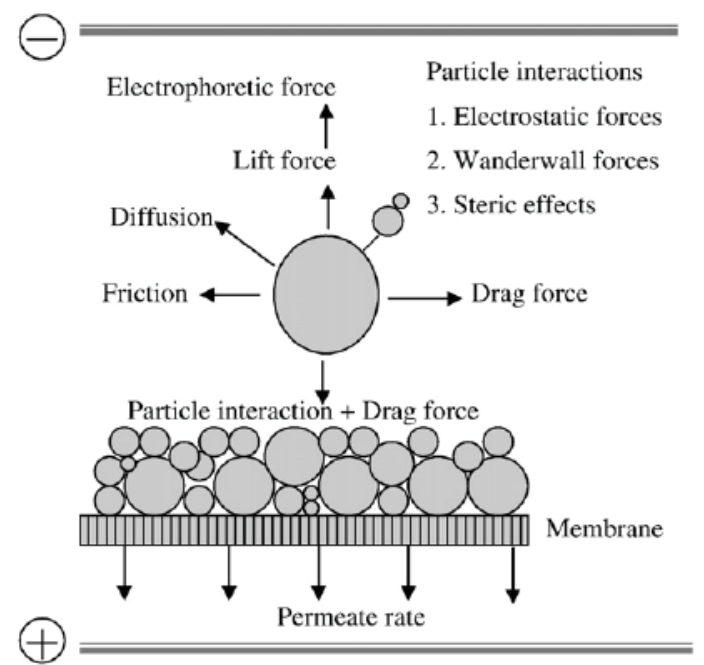

Fig. 4. Principles of electro-ultrafiltration.

and to increase the filtration flux, owing to electro-kinetic phenomena such as electrophoresis and electro-osmosis [81-86]. Basic principle of EUF is presented in Fig.4. This process aroused from a combination of number of mechanisms, including ion association, ion adsorption or ion dissolution. The electrochemical properties of the membrane surface and the dispersed materials or solutes can have a significant influence on the nature and magnitude of the interactions between the membrane and the used substances and their separation characteristics. The utilization of such properties by the application of external electric fields improved substantially the membrane performance. The accumulation of the solutes on the membrane surface is limited by the imposed electro-phoretic force. In addition, the filtration rate through the filter cake is dramatically enhanced due to electroosmosis as a secondary electro-kinetic phenomenon. This method is best suited for the separation of protein since its surface charge changes according to the solution $\mathrm{pH}$ [87-103]. As biological products like proteins and peptides are sensitive to shear stress and temperature, the coupled effects of electric field and pressure served as an additional driving force for the separation, which is an interesting way to improve the membrane permeates flux without increasing the shear stress $[81,102,103]$. Since proteins carry a net electrical charge, an electrical field may be used to reduce the influence of polarized layer. By applying a suitable external dc electric field, the protein molecules were transmitted through the membrane due to the electrostatic attraction and decline in concentration polarization. EUF was also studied as a membrane cleaning procedure, in which electrical fields attracted the particles with opposite charge from the membrane surface, and initial permeate flux was restored by eliminating fouling up to large extent. It was observed that as the voltage increased, the cake layers deposited on the membrane surface became thinner. Eventually when the critical voltage, at which the foulants were stationary reached no particle deposition on the membrane surface was observed [104]. Functionalizations of CS were carried out by either introducing phosphonic acid group or by quarternization of existing primary ammonium groups for making it water soluble biopolymer material. Negatively charged PC-Si and positively charged QC-Si membranes were prepared using 
TEOS and PVA as plasticizer by acid catalyzed sol-gel reaction in aqueous media. These membranes were gelated in the methanol under optimized conditions for tailoring the pore structure of the membrane. FTIR spectra and IEC study of the membranes confirmed the membrane conductivity, surface charge density and counter-ion transport number of the membranes also revealed mild charged nature. These membranes were employed for the separation of proteins from their mixture under coupled driving forces. It was concluded that separation of LYS from the mixture of BSA-LYS at pH: 4.8 (pI of BSA) using negatively charged PC-Si membrane or BSA from the mixture of BSA-LYS at pH 10.7 (pI of LYS) using positively charged PC-Si membrane, was possible with high selectivity. Also in all cases due to coupling of driving forces, filtrate flux and protein transmission was enhanced. Furthermore, applied electric gradient further progressively enhanced the separation factor (SF) suggested highly selective separation of protein under coupled driving forces. Protein transmission (selectivity) and membrane throughput across both membranes were studied using binary mixture of protein under different gradients at $\mathrm{pH}$ : 2.0, 4.8, 10.7, and 13.0. Furthermore, applied electric gradient progressively increased the SF, which was close to 10 for PC-Si and 15 for QC-Si membranes. Relatively high SF of individual protein from binary mixture and filtrate velocity suggests the practical usefulness of this novel process. BSA transmissions across both types of membranes and its effect on the $\mathrm{pH}$ of the feed protein solution were studied under coupled driving forces (pressure and electric gradient) in order to investigate the effect of nature of charge on the protein molecule (BSA), membrane matrix and direction of electric polarity applied. Schematic diagram for the different modes of protein transmission such as protein transmission using uncharged ultrafilter membrane without any electric gradient is presented in Fig. 5A. While Fig. 5B represents protein transmission under coupled driving forces using negatively charged ultrafilter membrane (PC-Si) and same for positively charged membrane (QC-Si) is depicted in Fig. 5C [105].
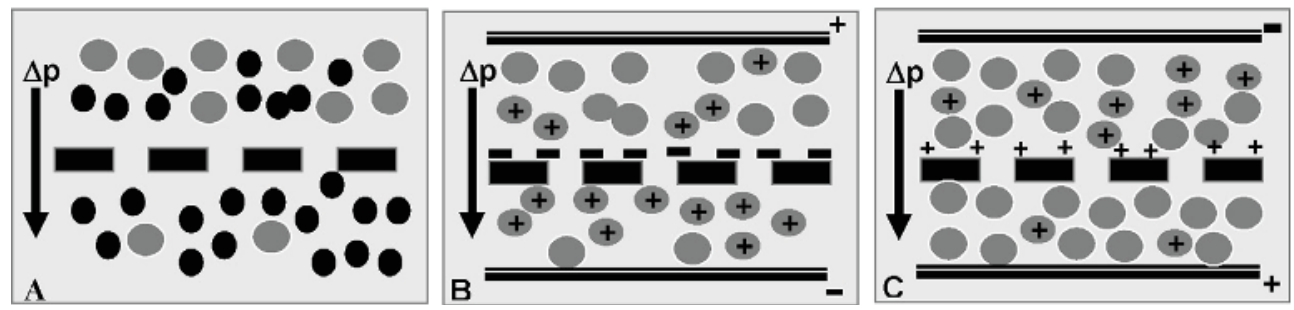

Fig. 5. Schematic presentation of: 6(A) Ultrafiltration; (B) ultrafiltration under applied potential gradient for CEM and (C) for AEM.

\section{Polymer electrolyte membranes for fuel cell applications}

The fuel cell (FC) is an electro-catalytic membrane reactor where the chemical energy of a fuel and an oxidant is continuously converted to electrical energy. The basic principle of a FC is not different than that of electrochemical batteries. However, in batteries the chemical energy is stored inside and conversion to electrical energy requires either disposal or recharge. In a FC, however, the chemical energy is provided by the fuel and an oxidant that stored outside the cell. Electrical energy can then be continuously produced as long as the fuel and the oxidant are provided. In a FC, the chemical energy is directly converted to electrical energy with efficiencies much higher than the conventional thermo-mechanical 
systems. In addition, FC operates without combustion and it is pollution free [106]. The FC is basically composed of two electrodes i.e. (anode and cathode) and an electrolyte. The energy conversion reaction occurs at the electrodes. The fuel is oxidized at the anode, the oxidant moves through the electrolyte and is reduced at the cathode. Hydrogen-oxygen $\left(\mathrm{H}_{2}-\mathrm{O}_{2}\right) \mathrm{FC}$, one of the most important fuel cell in which the hydrogen releases electrons and converted into the hydrogen ions $\left(\mathrm{H}^{+}\right)$. The $\mathrm{H}^{+}$ions permeate through the electrolyte and the electrons flow through an external load circuit to reach the air-electrode (cathode). On the cathode, $\mathrm{H}^{+}$ions, electrons and oxygen react to form water. The reaction take place at the electrode in FC is presented as:

$$
\begin{aligned}
& \text { Anode: } \mathrm{H}_{2} \rightarrow \mathrm{sH}^{+}+2 \mathrm{e}^{-} \\
& \text {Cathode: } 2 \mathrm{H}^{+}+1 / 2 \mathrm{O}_{2}+2 \mathrm{e}^{-} \rightarrow \mathrm{H}_{2} \mathrm{O} \\
& \text { Over all reaction: } \mathrm{H}_{2}+\mathrm{O}_{2} \rightarrow \mathrm{H}_{2} \mathrm{O}
\end{aligned}
$$

The nature of the electrolyte (liquid or solid) determines the operating temperature of a FC. The electrolyte blocks the electrons and prevents the electrical contact between the electrodes. It can either be a proton contactor or an oxygen ion contactor. The major difference between the two is the side of FC where the water is produced. When a proton conductor is used, the water is produced in the cathode side of FC. The FC systems are commonly distinguished by the type of electrolyte applied, in the following categories: alkaline fuel cells (AFC), phosphoric acid fuel cells (PAFC), molten carbonate fuel cells (MCFC), solid oxide fuel cells (SOFC) and polymer-electrolyte fuel cells (PEFCs). In this chapter, we focus on the PEFCs where a polymeric membrane is used as electrolyte. The $\mathrm{H}_{2} / \mathrm{O}_{2}$ fuel cell, commonly referred to as polymer electrolyte fuel cell (PEFC) and the direct methanol fuel cell (DMFC) are the two types of fuel cells which use polymer electrolytes. DMFCs have higher energy density but exhibit shortcomings such as (a) slower oxidation kinetics than PEFC below $100^{\circ} \mathrm{C}$ and (b) significant permeation of the fuel from the anode to the cathode resulting in a drop in efficiency of fuel utilization up to $50 \%$ [107]. In order to improve fuel cell performance, it is essential to understand the effect of operating parameters on fuel cell performance. Membrane is the core component of polymer electrolyte membrane (PEM) fuel cell. To achieve high efficiency, membrane must possess the following desirable properties: (i) high proton conductivity to support high currents, (ii) resistive losses and zero electronic conductivity, (iii) adequate mechanical strength and stability, (iv) chemical and electrochemical stability under operating conditions, and (v) moisture control in stack.

A series of cross-linked CS sulfate membranes have been developed by grafting CS monomers with $-\mathrm{SO}_{3} \mathrm{H}$ groups and then cross-linked the polymers by the reaction between $-\mathrm{SO}_{3} \mathrm{H}$ groups in CS sulfate and the amido groups in pure CS [108]. Although these types of membranes do not offer significant advantages over Nafion, as far as proton conductivity concerned and a significant reduction in methanol permeability make these polymers appeared to be suitable for DMFCs applications [109].

The ratio between PVA and CS in the substrate membrane varied in order to determine an optimal substrate for the reduction in methanol crossover. The pore filling developed membranes were characterized in terms of methanol permeability and conductivity. The composition ratio between PVA and CS can affect the proton conductivity. The developed 
composite membranes were also tested for methanol permeability [110]. The ionic crosslinking occurred on blending the polyelectrolyte that excludes the need of using other crosslinking agents. The study thus reveals the possibility of preparing low cost acid-base polyelectrolyte blend membranes having IEC comparable to that of Nafion but relatively lower methanol permeabilities. New polymer electrolyte composite membranes were prepared by using CS as the matrices and incorporating potassium hydroxide for ionic functionality [111].

Hybrid membranes were prepared from CS as organic matrix and surface-modified Y zeolite as inorganic filler. Membranes were tested for their applicability for use in DMFC by methanol permeability, proton conductivity and swelling property [112].

Two series of novel cross-linked composite anion exchange membranes were prepared using different mass of QAPVA and HACC and using GA as the cross-linking reagent [113]. The quaternary ammonium group grafted onto the matrix of quaternized poly(vinyl alcohol) (QAPVA) and quaternized CS (2-hydroxypropyltrimethyl ammonium chloride chitosan, (HACC) composite membranes have exchangeable anions. Novel cross-linked composite membranes were investigated for their applicability in alkaline membrane fuel cells.

The composite membranes showed a high conductivity $\left(10^{-3}\right.$ to $10^{-2} \mathrm{Scm}^{-1}$ along with low methanol permeability (from $5.68 \times 10^{-7}$ to $4.42 \times 10^{-6} \mathrm{~cm}^{2} \mathrm{~s}^{-1}$ ) at $30^{\circ} \mathrm{C}$. It was concluded that membrane structure was the principal factor for affecting the conductivity and methanol permeability of membranes. A series of quaternized-chitosan derivatives (QCDs) with various degrees of quarternization was synthesized using glycidyltrimethylammonium chloride as a main quaternized reagent [114]. These QCDs were then processed into hydroxide by dipping the resultant membranes in aqueous potassium hydroxide solutions. The resultant anion-exchange membranes in hydroxide form were further cross-linked by using ethylene glycol diglycidyl ether as a cross-linker. An anhydrous proton conducting membrane was prepared from CS, which possesses a large proton exchange capacity. The composite membrane (CS-200 wt\% MP) showed the high proton conductivity $\left(5 \times 10^{-3} \mathrm{~S}\right.$ $\mathrm{cm}^{-1}$ ) at $150^{\circ} \mathrm{C}$ under anhydrous conditions [115]. Additionally, the proton conduction mechanism of the composite membrane was attributable due to proton transfer into the proton defect site without the assistance of diffusible vehicle molecules. The utilization of a biopolymer, such as CS for PEMFC technologies is novel and challenging where biological products are usually considered as waste, non-hazardous, and environmentally benign. Especially, the low production cost of the biopolymer is an attractive feature.

Zeolite beta particles with different sizes and narrow size distribution were hydrothermally synthesized and incorporated into CS matrix to prepare CS/zeolite beta hybrid membranes for DMFC [116]. Interfacial interaction between modified-zeolite-filled chitosan membranes has been illustrated in Fig. 6.

Sultone precursor (1,3-propane sultone (PS)) directly endowed the sulfonic acid groups from ring opening of sultone and did not need further treatment after the surface functionalization of zeolite beta particles. In the case of phenyl group precursor phenyl trimethoxy silane (PTMS), the phenyl groups grafted onto zeolite beta further reacted with concentrated sulfuric acid at $80{ }^{\circ} \mathrm{C}$. As for thiol precursor i.e. mercaptopropyl trimethoxy silane (MPTMS), the mercapto groups was grafted onto zeolite beta and then oxidized into $-\mathrm{SO}_{3} \mathrm{H}$ groups with $\mathrm{H} 2 \mathrm{O} 2$ solution at $25^{\circ} \mathrm{C}$. Then sulfonated zeolite beta particles were incorporated into CS membrane matrix. Then the membranes were characterized and found 


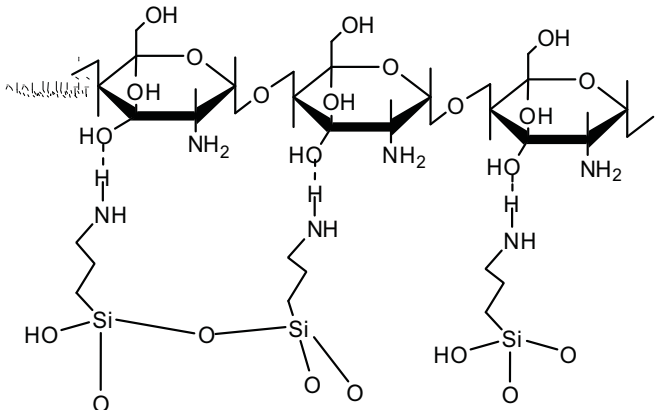

(a)

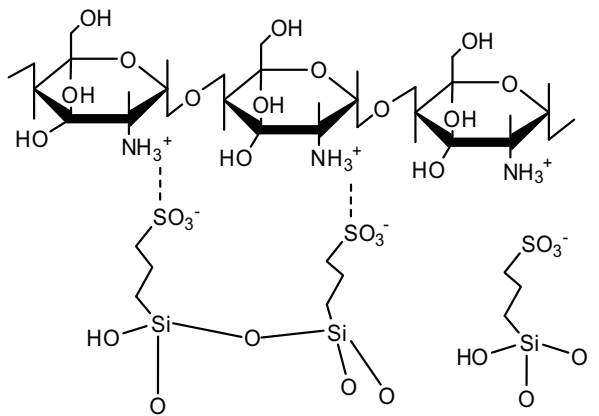

(b)

Fig. 6. Schematic presentation of interfacial interaction between modified-zeolite-filled chitosan membranes (a) CS- $\mathrm{H}_{2} \mathrm{NY}$ membranes and (b) CS- $\mathrm{HO}_{3} \mathrm{SY}$ membranes

that the introduction of $-\mathrm{SO}_{3} \mathrm{H}$ groups could reduce the methanol permeability further as a result of the enhanced interfacial interaction between zeolite beta particles and CS matrix. Further sulfonation of zeolite beta particles improved their compatibility with CS matrix through increasing the ionic interaction between $-\mathrm{SO}_{3} \mathrm{H}$ groups and $-\mathrm{NH}_{2}$ groups. Thereby, most of CS/beta- $\mathrm{SO}_{3} \mathrm{H}$ hybrid membranes showed lower methanol permeability and higher selectivity than CS/beta hybrid membranes. However, their proton conductivity changed only a little, indicating that the vehicle mechanism was dominant in proton conduction. Considering low methanol permeability, moderate proton conductivity, high selectivity, environmental benignity, low cost as well as facile fabrication, CS membranes filled by zeolite beta, especially sulfonated zeolite beta, showed a promising potential for DMFC applications [117]. CS served as catalyst support for Pt particles. LBL films of CS may also be used in hybrid cells with a Nafion membrane, in which synergism is sought between the properties of Pt in self-assembled films and Nafion membranes.

The CS membranes were prepared from CS flakes extracted from the exoskeleton of Cape rock lobsters, and were cross-linked with $\mathrm{H}_{2} \mathrm{SO}_{4}$ [118]. The four composite membranes i.e. CS/ heteropolyacids (HPAs), CS/ phosphomolybdic acid (PMA), CS/phosphotungstic acid (PWA) and CS/silicotungstic acid (SiWA)) were prepared by an infiltration and selfassembly method [119]. The methanol permeability of CS/PMA composite membrane was approximately two times higher than Nafion 117. Among the all membranes, CS/PMA membrane was identified as ideal candidate for DMFC applications as it exhibited low methanol permeability $\left(2.7 \times 10^{-7} \mathrm{~cm}^{2} \mathrm{~s}^{-1}\right)$ and comparatively high proton conductivity $(0.015$ $\mathrm{S} \mathrm{cm}^{-1}$ at $25^{\circ} \mathrm{C}$ ). Thus, CS/HPAs composite membranes were promising proton-conducting materials and have great potential for use in DMFCs application [120]. The effects of zeolite pore size, particle size, hydrophilic/hydrophobic nature, and zeolite content on the membrane performance were explored. The transport of methanol in all the as-prepared membranes was mainly controlled by the diffusivity [121]. Hydrophobic zeolite with a relatively high $\mathrm{Si} / \mathrm{Al}$ ratio preferentially adsorbed methanol by London force, leading to decreased water uptake, swelling, free volume cavity size and methanol permeability but increased methanol uptake. Meanwhile, the proton conductivity was slightly decreased with zeolite content due to the decrease of water content in the membranes. The hybrid 
membranes displayed desirable thermal and mechanical stabilities within the working temperature range of DMFC. Solid superacid $\left(\mathrm{STiO}_{2}\right)$ particles into CS-intermolecular interactions between $\mathrm{STiO}_{2}$ and CS segmental chains were confirmed by FTIR image, suggesting that the addition of sulfate ions into $\mathrm{TiO}_{2}$ particles might be retard the crystallization during the calcinations procedure. The results confirmed that $\mathrm{STiO}_{2}$ particles $(10 \mathrm{~nm})$ as inorganic filler were successfully incorporated into the CS membrane matrix. Meanwhile, due to the interfacial interactions between $\mathrm{STiO}_{2}$ and CS chains, the hybrid membranes exhibited an enhanced mechanical strength and adequate thermal stability as verified by mechanical strength characterization and thermo-gravimetric analysis. Consequently, $\mathrm{CS} / \mathrm{STiO}_{2}$ hybrid membranes acquired higher selectivity compared with control CS membrane [121]. New polymer electrolyte composite membranes were prepared by using $\mathrm{CS}$ as the matrices and incorporating $\mathrm{KOH}$ for ionic functionality. These membranes had a three-layer structure, which consists of a porous intermediate layer and two cross-linked solid surface layers. Their ionic-conductive properties were investigated using impedance spectroscopy. All fuel cells showed an open-circuit potential around some possible improvements on the performance of the resultant fuel cells were also found. Proton conducting cross-linked complex membranes was prepared by blending of a cationic polyelectrolyte, i.e. CS and an anionic polyelectrolyte, i.e. poly (styrenesulfonic acid-comaleic acid) (PSSA-MA). The synthetic procedure for cross-linked CS/PSSA-MA membranes is illustrated in Scheme 2. CS contain two functional groups, i.e. hydroxyl $(-\mathrm{OH})$ and amine $\left(-\mathrm{NH}_{2}\right)$ whereas PSSA-MA contains two acids, i.e. strong acid $\left(-\mathrm{SO}_{3} \mathrm{H}\right)$ and weak acid $(-\mathrm{COOH})$. Thus, two interactions occurred in blend membranes. The other was the complex formation between $-\mathrm{NH}_{2}$ of $\mathrm{CS}$ and $-\mathrm{SO}_{3} \mathrm{H}$ of PSSA-MA. Thus the PSSA-MA acted as a cross-linker and a proton conductor in the blend membranes. The interaction between CS and PSSA-MA was confirmed by FTIR study. The minimum water uptake and conductivity were attributed to the competitive effect between the formation of crosslinking/complex and the concentration of ionic groups in the membrane matrix. All the membranes exhibited temperature dependent proton conductivity, i.e. the increase of conductivity with temperature. Furthermore, CS is an extremely cheap, nonhazardous, and environmentally polymer which is advantageous over other polymer electrolyte membranes in terms of the green technology fuel cells [122]. Polymer electrolyte complexes of CS and poly vinyl phosphonic acid (PVPA) were prepared by in situ polymerization of vinyl phosphonic acid (VPA) in CS matrix [123]. Polybenzamidazole (PBI) and sulfuric acid $\left(\mathrm{H}_{2} \mathrm{SO} 4\right)$ composite membranes were prepared and the exclusion problem was observed especially in $\mathrm{PBI} / \mathrm{H}_{3} \mathrm{PO}_{4}$ composite membranes [124]. Sulfonated polysulphone (SPSF) /CS exhibited high IEC and proton conductivity higher than Nafion 117 at temperature above $100^{\circ} \mathrm{C}$. The membrane also showed adequate geometrical and thermal stabilities and can therefore be considered as a potential alternative fuel cell membrane especially for high temperature operations. The modification of CS was carried out by introducing $-\mathrm{PO}_{3} \mathrm{H}_{2}$ group and composite membranes were prepared by blending the phosphonated CS and PVA of different compositions [125]. Then the membranes were cross-linked by $\mathrm{HCHO}$ as cross-linker by formal reaction. All these bonds exhibited affinity towards water and repel organic molecules such as methanol, which leads to the hydration of polymer matrix with enhanced water retention. NMPC/PVA composite biomaterial was used for the membrane preparations with known composition. 


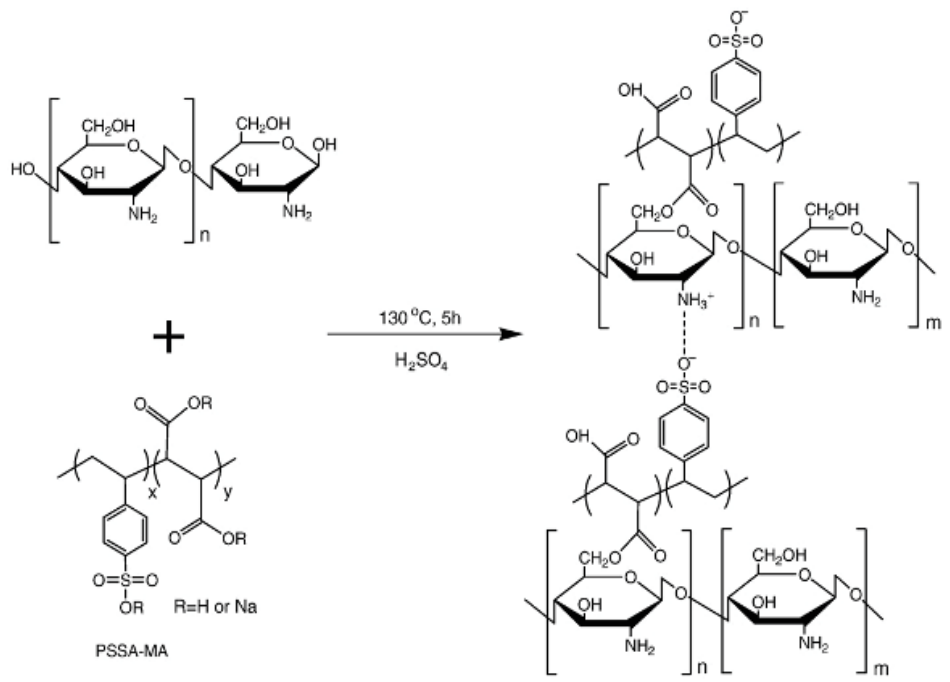

Scheme 2. Synthetic procedure for the cross-linked membranes consisting of CS and PSSAMA.

Novel cross-linked composite membranes were synthesized to investigate their applicability in AEM fuel cells [126]. These membranes consist of QAPVA and HACC with glutaraldehyde as the cross-linking reagent. With the quaternary ammonium group grafted onto the matrix of QAPVA and HACC, the composite membranes possessed exchangeable anions [127]. PEC membrane for DMFCs was also prepared by blending a cationic polyelectrolyte, CS with an anionic polyelectrolyte, acrylic acid-2-acrylamido-2methylpropane sulfonic acid copolymer (P(AA-AMPS)) [128]. The CS/P(AA-AMPS) membrane with a $\mathrm{P}(\mathrm{AA}-\mathrm{AMPS})$ content of $41 \mathrm{wt}$ \% exhibited a methanol permeability $(P)$ of $2.41 \times 10^{-7} \mathrm{~cm}^{2} \mathrm{~s}^{-1}$ which was fifteen times lower than that of Nafion ${ }^{\circledR} 117$ where as its proton conductivity $(\sigma)$ was comparatively high $\left(3.59 \times 10^{-2} \mathrm{~S} \mathrm{~cm}^{-1}\right)$. In terms of the overall selectivity index $(\beta=\sigma / P)$, the PEC membrane showed a remarkably higher selectivity than Nafion ${ }^{\circledR} 117$ and, furthermore, the overall selectivity index increased with the increase of P(AA-AMPS) content. This kind of PEC membranes jointly utilized the methanol-rejecting property of one polyelectrolyte and the proton-conducting property of the other polyelectrolyte showed a promising application for DMFCs [129-132]. Organic-inorganic nanostructured composites constitute an emerging research field, which has opened the possibility of tailoring new materials because they combine in a single solid both the attractive properties of a mechanically and thermally stable inorganic backbone and the specific chemical reactivity and flexibility of the organo functional groups. Reports are available for diversified applications of CS inorganic hybrid nanostructured material. Blended PEM of CS with zeolite was also reported [133-139]. But mechanical stability and leaching out are serious problems for their prolonged use. It was expected that grafting of aromatic ring and less acidic - $\mathrm{COOH}$ groups on CS moiety will balance its hydrophilichydrophobic nature and enhance proton conducting properties [140]. The distribution of silica particles within the membrane matrix was assessed by TEM study. This provides evidence that these hybrid membranes have nanosized silica particles homogeneously 
distributed within the polymer matrix. The main advantage of preparing hybrid membrane by the sol-gel method was uniform homogeneous distribution. These results suggest that the uniform hybrid membrane with nanosized silica and $-\mathrm{SO}_{3} \mathrm{H}$ clusters in the membrane matrix. The activation energy (Ea) increased significantly with the increase in NCBC-silica content in the membrane phase. In all cases, $2.0 \mathrm{~h}$ cross-linked membranes with the same compositions showed maximum $E$ a. The $E_{a}$ of the prepared membranes were slightly higher than that of Nafion117. Thus, the thermal activated conduction process for prepared composite membranes was higher in comparison with Nafion117 membrane. At higher temperature, fast proton and water molecule diffusion resulted in a rapid conduction process, due to the more continuous pathway because of interlinking of hydrophilic channels. Furthermore, comparable Ea values of prepared and Nafion117 membranes indicated a Grotthus-type conduction mechanism. The performance of PCS-3-3 membrane was tested by recording current-voltage polarization curves in DMFCs under different experimental conditions with varying methanol concentrations $(20,30$, and $50 \% \mathrm{MeOH})$ in feed at $70{ }^{\circ} \mathrm{C}$ (Fig. 7A). The variations of power density with current density are also presented in Fig. 7(B) under similar experimental conditions.
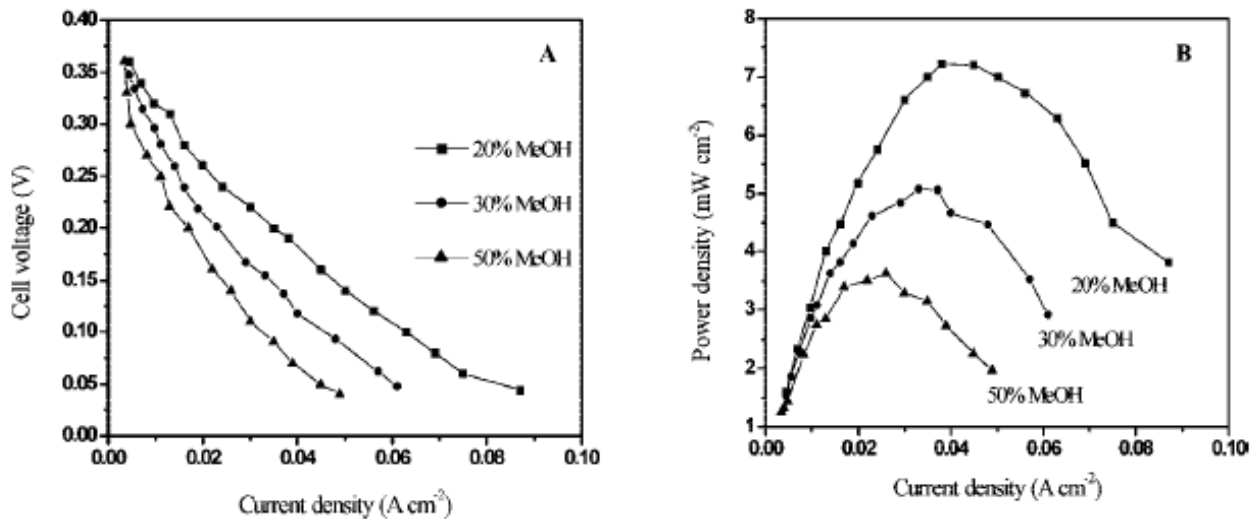

Fig. 7. Current-voltage polarization curves for PCS-3-3 membrane with varying methanol concentration at $70^{\circ} \mathrm{C}$ in air mode.

At low methanol concentration, low methanol crossover increased the open circuit voltage (OCV) and significantly improved the performance. In this study, all polyelectrolyte membranes showed almost comparable OCV $(0.35 \mathrm{~V})$. The current density for PCS-3-3 at the different methanol concentrations was measured at about 38, 35, and $26 \mathrm{~mA} \mathrm{~cm}^{-2}$.

The nanostructure hybrid material was prepared from sepiolite with the cationic biopolymer CS. The strong interaction occurred between them after blending to each other and enhanced the thermal stability of the CS-sepiolite nanocomposite. Thus, the new CS-sepiolite hybrid materials are processed as self-supporting films that could potentially be used in different applications such as separation processes of gas mixtures, components for electrochemical sensors, or membranes in fuel-cell devices [141]. New PEM composite membrane comprises of CS, PVA and calcium oxide $(\mathrm{CaO})$ were fabricated. The effect of $\mathrm{CaO}$ particle addition into CS-PVA on conductivity and the feasibility of membranes for DMFC application were also carried out. The $\mathrm{CaO}$ particles have the profound effect on the CS-PVA membrane conductivity. These results indicated that CS-PVA-CaO composite membrane have excellent 
methanol barrier properties and found to be feasible for DMFC applications [142]. CS complex membranes were prepared and characterized at room temperature [143]. Fluorescence measurements were correlating the improved activity to alterations in the amphiphilic nature of the chemical microenvironment (immediately surrounding the enzyme) that the modified CS affords [144]. Phosphorylated CS membranes were prepared from the reaction of orthophosphoric acid and urea on the surface of CS membranes in N,N-dimethylformamide [143]. Membrane based on stabilized phosphotungstic acid (PTA) incorporated to chitosan (CS)-hydroxy ethyl cellulose (HEC) for application in direct methanol fuel cells (DMFCs) was reported. Membranes were characterized using FTIR, TGA, SEM and their mechanical properties were also evaluated. The PTA content in the CS-HEC blend membrane and its influence on proton conductivity, water/methanol sorption, and methanol cross-over in the DMFC was studied. The PTA-CS-HEC mixed matrix 3 (wt. \%) stabilized membrane used in DMFC testing delivered peak power density of $58 \mathrm{mWcm} 2$ at a load current [145].

\section{Chitosan based polymer electrolyte membranes for pervaporation (PV)}

PV is a relatively new membrane separation process that has elements in common with reverse osmosis and membrane gas separation. In pervaporation, the liquid mixture to be separated (feed) is placed in contact with one side of a membrane and the permeated product (permeate) is removed as a low pressure vapor from the other side. The permeate vapor can be condensed and collected or released as desired. The chemical potential gradient across the membrane is the driving force for the mass transport. Pervaporation transport is usually described to be a three-step process: solution-diffusion-evaporation. The separation is based on the selective solution and diffusion. In developing pervaporation membranes, three issues must be addressed: (i) membrane productivity, (ii) membrane selectivity, and (iii) membrane stability. Membrane productivity is a measure of the quantity of a component that permeates through a specific area of membrane surface in a given unit of time. Membrane productivity is frequently characterized by permeation flux, J, which relates the product rate to the membrane area required to achieve the separation. Note that permeation flux depends on both the intrinsic permeability and the effective thickness of a membrane. The commercialization of the pervaporation technique is, to a large extent, attributed to the engineering approach of making thin membranes in asymmetric and composite forms. When the separation factor is unity, no separation occurs [146]. The silica CS membrane modified with functionalized silica (CSM-5 and CSM-10) were more suitable for the pervaporation and dehydration of ethanol/ aqueous mixture solution. Organicinorganic hybrid membranes with various TEOS contents from quaternized CS - tetra ethoxy silane ( $q$-Chito- TEOS) were prepared by sol-gel reaction [147]. This study suggested that the preparation of organic-inorganic hybrid membranes for the dehydration of an azeotropic mixture of ethanol/water was possible by minimizing membranes swelling which was accomplished by controlling TEOS content in the hybrid membrane matrix (Fig.8.). The CS membrane was modified with oppositely charged surfactants such as sodium dodecyl sulfate (SDS), sodium laurate (SL), sodium stearate (SS), dioctyl sodium sulfosuccinate (DSS) and amphoteric sodium N-lauroyl sarcosinate (SLS) [148]. The developed membranes were used for the separation of water-isopropanol mixtures at different temperatures. The highest separation selectivity was found to be 31,648 with a flux of $4.4 \times 10^{-2} \mathrm{~kg} \mathrm{~m}^{-2} \mathrm{~h}^{-1}$ for membrane (M-3) at $30^{\circ} \mathrm{C}$ for 5 mass $\%$ of water in the feed. 


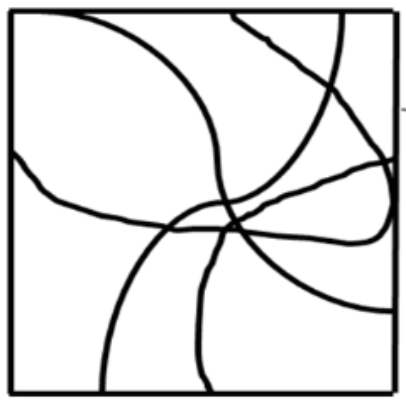

q - Chitosan

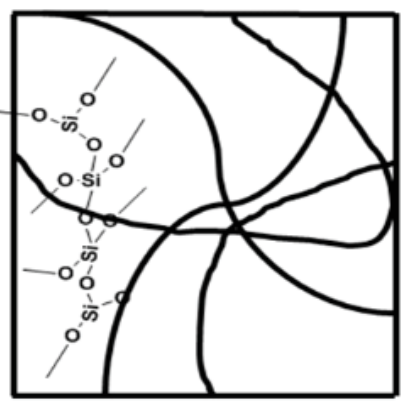

TEOS $<45 \%$

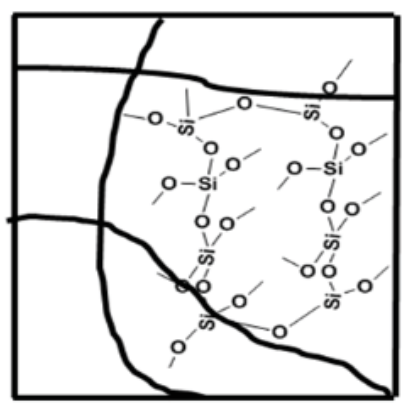

TEOS $>45 \%$

Fig. 8. Change of cross-linked structure in q-chitosan/TEOS hybrid membranes.

Significantly activation energy for water $\left(E_{\mathrm{pw}}\right)$ lower than that of isopropanol $\left(\mathrm{E}_{\mathrm{pIPA}}\right)$ suggested high separation ability for developed PECs membranes. Huang et al. prepared composite CS membranes on porous polyetherimide substrate support for the pervaporation separation of ethanol/toluene and methanol/toluene mixtures [149]. The CS membranes were acetylated in various concentrations of acetic anhydride solutions. The developed membranes were mechanically robust and stable to withstand the corrosive nature of ethanol/toluene mixture during the PV experiments. Developed composite membranes were considered as good candidate for PV separation of organic/organic liquid mixture. Homogeneous polyelectrolyte complex membranes (HPECMs) were fabricated by poly electrolyte complexes (PECs): CS/ sodium carboxymethyl cellulose (CMCNa) in aqueous $\mathrm{NaOH}$ solution [150]. $\mathrm{TiO}_{2}$ particles were generated at the nanosized level, and dispersed homogeneously within the polymer matrix without aggregation even at high $\mathrm{TiO}_{2}$ content. CS/ $\mathrm{TiO}_{2}$ nanocomposite membranes were considered as good candidate for the separation of ethanol from ethanol and water mixture.

CS/PSF composite membrane was prepared in order to enhance the permeation rate [151]. CS composite membranes were prepared by casting CS solution onto a porous poly(ether sulfone) (PES) based ultra-filtration membrane with various surface cross-linking densities. The surface cross-linked CS composite membranes exhibited a high selectivity with a low permeation flux for the dehydration of water-alcohol mixtures by PV. Permeate flux and water concentration in the permeate decreased drastically with feed of ethanol concentration greater than $97 \mathrm{wt} \%$. Permeation rate of CS composite membranes was less temperature dependent than that of PVA. IPA-water mixture was similar tendency as that of ethanol-water mixture in pervaporative dehydration performances [152]. Nwawi et al. prepared homogeneous and composite CS membranes by solution casting technology [153]. The composite CS/PSF composite membrane exhibited an advantage over the homogeneous when the isopropanol concentration in feed solution was increased more than 70\%. CS-silica hybrid membranes (CSHMs) were prepared by cross-linking of CS by using 3-aminopropyl-triethoxysilane (APTEOS) as cross-linker to enhance flux and selectivity [154]. PV separation performance of water-ethanol by using the CS membrane was clearly correlated with the crystal property aroused from the preparation temperature. The prepared membranes showed the best separation index at 323K temperature. CS membranes were converted into its free amine form [155]. Devi et al. prepared novel cross-linked CS/poly(vinylpyrrolidone)(PVP) blend membranes for the dehydration of tetrahydrofuran (THF) by PV. Blend membrane was cross- 
linked with glutaraldehyde, followed by further cross-linking with sulfuric acid to improve the membrane resistivity towards water-rich media [156]. Won et al. prepared CS membranes and cross-linked by sulfuric acid. Dimethyl carbonate (DMC) an environmentally benign chemical is commercially produced by oxidative carbonylation of methanol, and the separation and purification of DMC is critical for the production of DMC due to azeotropic nature of the reaction mixtures. The membranes were tested for separation of binary $\mathrm{DMC} /$ water, $\mathrm{DMC} /$ methanol and methanol/water mixtures and ternary $\mathrm{DMC} /$ methanol/water mixtures in a temperature range of $25-55^{\circ} \mathrm{C}$. It was found that coupling effect was important in PV separation of multi-component mixtures due to interactions among the permeating species [157]. CS homogeneous membrane, PVA-poly (acrylonitrile) (PVAPAN) and CS-PVA/poly (acrylonitrile) (CS-PVA/PAN) composite membranes were prepared for the separation of ethanol-water solutions [158].

Bacterial cellulose membrane (BCM) impregnated with CS based membrane was prepared and designated as CS-BCM. Then the modified membrane was used for the separation of ethanol/water $\left(\mathrm{EtOH} / \mathrm{H}_{2} \mathrm{O}\right)$ azeotrope by $\mathrm{PV}$. The effect of temperature on selectivity and flux through CTSN-BCM was also investigated. It was concluded that the developed CSBCM based membrane can be an alternate for use in PV dehydration of $\mathrm{EtOH} / \mathrm{H}_{2} \mathrm{O}$ azeotrope mixture [159]. Sodium zeolite-Y (NaY zeolite) filled CS polymeric membranes were developed and characterized for the PV dehydration performances [160].

\section{Conclusions}

Interest in chitin was initially cultivated mainly by zoologists, marine entomologists, and physiologists, but in the late 1970s, chemists all over the world devoted attention to chitin. In particular, it was immediately realized that chitin was an abundant source of chitosan, the unique cationic polysaccharide (as opposed to a variety of easily accessible anionic polysaccharides), and, as such, was superior to man-made cationic derivatives of cellulose and starch. Chitin and its primary derivative chitosan, biopolymers from renewable resources (shells of shellfish, the wastes of the seafood industry), offer a distinct set of advantageous biological and physico-chemical characteristics that qualify them for a multiplicity of industrial, biotechnological, medical, food industry, separations and applications for energy devices such as fuel cell. These membrane processes are contributing to cleaner industries, a cleaner environment, water and food. The effective wide applications of chitosan based materials or membranes; however, becoming possible once the manufacture of chitinous materials of standardized characteristics has been worked out.

The distinctive advantages of chitosan include availability, biocompatibility, biodegradability, non-toxicity, antimicrobial properties, heavy metal ions chelation, gel forming properties, ease of chemical modification, and high affinity to proteins. These characteristics of the polymer (chitosan) can be widely exploited in the near future in environmentally benign membrane based applications for environment, bio-technology and energy devices. This Chapter looks at how chitin/chitosan materials can contribute to the development of membrane-based processes.

\section{Acknowledgements}

Authors are thankful to Dr. P. K. Ghosh, Director, CSMCRI, Bhavnagar-364002, India for his encouragements and supports. 


\section{References}

[1] E. Chiellini, F. Chiellini, P. Cinelli, in: G. Scott (Ed.), Kluwer, Dordrecht, 2002, p. 163.

[2] S.M. Hudson, C. Smith, in: D.L. Kaplan (Ed, Springer, Berlin, 1998, p. 96.

[3] K. Kurita, Prog. Polym. Sci. 26 (2001) 1921.

[4] J.A. Howell, Desalination 144 (2002) 127.

[5] Q. Li, E.T. Dunn, E.W. Grandmaison, M.F.A. Goosen, J. Bioact. Comp. Polym. 7 (1992) 379.

[6] M. Peter, J. Macromol. Sci. Pure Appl. Chem. A32 (1995) 629.

[7] W. Paul, C.P. Sharma, STP Pharma Sci. 10 (2000) 5.

[8] A.K. Singal, M. Chawla, Pharm. Pharmacol. 53 (2001) 1047.

[9] M. Minoru, S. Hiroyuki, S. Yoshihiro, Trends Glycosci. Glycotechnol. 14 (2002) 205.

[10] M.N.V.R. Kumar, React. Funct. Polym. 46(2000) 1.

[11] E. Guibal, Sep. Purif. Technol. 38(2004) 43.

[12] A.J. Varma, S.V. Deshpande, J.F.Kennedy, Carbohydr. Polym. 55 (2004) 77.

[13] C. Gerente, V.K.C. Lee, P.L. Cloirec, G. McKay, Crit. Rev. Environ. Sci. Technol. 2007;37:41.

[14] G. Crini, P.M. Badot, Prog. Polym. Sci. 33 (2008) 399.

[15] P. Miretzky, A. C. Fernandez, J. Hazard. Mater. 167 (2009) 10.

[16] G. Crini, Prog. Polym. Sci. 30 (2005) 38.

[17] J. Ramirez-Salgado, Electrochim. Acta 52 (2007) 3766.

[18] B.P. Tripathi, V.K. Shahi, J. Phys. Chem. B 112 (2008) 15678-15690.

[19] P. Mukoma, B.R. Jooste, H.C.M. Vosloo, J. Power Sources 136 (2004) 16-23.

[20] T. Uragami, Polysaccharides, Marcel Dekker, New York, 1998, p. 887.

[21] T. Uragami, K. Takigawa, Polymer 31 (1990) 668.

[22] Y.-L. Liu, C.-Y. Hsu, Y.-H. Su, J.-Y. Lai, Biomacromolecules 6 (2005) 368.

[23] N.L. Nemerrow, Liquid waste of industry. California: Addison Wesley Publishing Company; 1971.

[24] F.W. Pontius, Water quality and treatment. $4^{\text {th }}$ Ed. New York: McGraw-Hill, Inc.; 1990.

[25] S. Chatterjee, S.H.Woo, J. Hazard. Mater. 164(2009) 1012.

[26] R. Yao, F. Meng, L. Zhang, D. Ma, M.Wang, J. Hazard. Mater. 165(2009) 454.

[27] G.Z. Kyzas, M. Kostoglou, N.K .Lazaridis, Chem. Eng. J. 152(2009) 440.

[28] S. Jagtap, D. Thakre, S. Wanjari, S. Kamble, J. Colloid Interface Sci. 332 (2009) 280.

[29] P. Monvisade, P. Siriphannon, Appl. Clay. Sci. 42 (2009) 427.

[30] G. Crini, B. Martel, G. Torri, Int. J. Environ. Pollut. 34 (2008) 451.

[31] A.C. Chao, S.S. Shyu, Y.C. Lin, F.L. Mi, Bioresour. Technol. 91(2004) 157.

[32] R. Bassi, S.O. Prasher B.K. Simpson, Sep. Sci. Technol. 35 (2000) 547.

[33] E. Guibal, C. Milot, J.Roussy, Water Environ. Res. 71(1999)10.

[34] E. Guibal C. Milot, J.M. Tobin, Ind. Eng. Chem. Res. 37(1998) 1454.

[35] L. Dambies, A. Roze, E. Guibal Adv. Chitin. Sci. 4 (2000) 302..

[36] M.L. Arrascue, H.M. Garcia, O. Horna, E.Guibal Hydrometallurgy 71 (2003)191.

[37] V.A. Spinelli, M.C.M. Laranjeira, V.T. Favere, React. Funct. Polym. 61(2004) $347 .$.

[38] M. Kumar, B. P. Tripathi, V. K. Shahi, J. Hazard. Mater. 172 (2009) 1041.

[39] S. Hasan, A. Krishnaiah, T. K. Ghosh, D. S. Viswanath, Ind. Eng. Chem. Res. 45 (2006) 5066.

[40] C. Jeon, W.H.H. Holl, 37 (2003) 4770.

[41]A. Atia, Hydrometallurgy 80 (2005) 13.

[42] J. Song, J. Li, D. Wang, Y. Wang, Ion Exchange Adsorption 24 (2008) 175. 
[43]A.M. Donia, A. Atia, K.Z. Elwakeel, J. Hazard. Mater. 151 (2008) 372.

[44] L. Hakim, A. Sabarudin, K. Oshita, M. Oshima, S. Motomizu, Talanta 76 (2008) 1256.

[45] W. S. W. Ngah, K. H. Liang, Ind. Eng. Chem. Res. 38 (1999) 1411.

[46] C. Septhum, S. Rattanaphani, J.B. Bremner, V. Rattanaphani, J. Hazard. Mater. 148 (2007) 185.

[47] S. Sun, L. Wang, A. Wang, J. Hazard. Mater. B136 (2006) 930.

[48] N. Li, R. Bai, Ind. Eng. Chem. Res. 45(2006)7897.

[49] F. Zhao, B. Yu, Z. Yue, T. Wang, X. Wen, Z. Liu, C. Zhao J. Hazard. Mater.147 (2007) 67.

[50] K. C. Justi, V. T. Favere, M. C.M. Laranjeira, A. Neves, R. A. Peralta, J. Colloid Interface Sci. 291 (2005) 369.

[51] K. C. Justi, M. C.M. Laranjeira, A. Neves, A. S. Mangrich, V. T. Favere, Polymer 45 (2004) 6285.

[52] R. L. Machado, E. J. de Arruda, C. C. Santana, S. M. A. Bueno, Process Biochemistry 41 (2006) 2252.

[53] F. Zha, S. Li, Y. Chang, J. Yan, J. Membr. Sci. 321 (2008) 316

[54]A. Saxena , A. Kumar, V. K. Shahi, J. Colloid Interface Sci. 303 (2006) 484.

[55]C.L.de Vasconcelos, P.M. Bezerril, T.N.C. Dantas, M.R. Pereira, and J.L.C. Fonseca, Langmuir 23(2007) 7687.

[56] H.-D. Wang, L.-Y. Chu, H. Song, J.-P. Yang, R. Xie, J. Membr. Sci.297 (2007) 262.

[57]V.P. Hoven, V.Tangpasuthadol, Y. Angkitpaiboon, N. Vallapa, S. Kiatkamjornwong, Carbohydrate Polymers 68 (2007) 44.

[58] X. Chen, J. Liu, Z. Feng, Z. Shao, J. Appl. Polym. Sci. 96(2005) 1267.

[59] W. Shi, Y.Q. Shen, D.T. Ge, M.Q. Xue, H.H. Cao, S.Q. Huang, J.X. Wang., G.L. Zhang, F. B. Zhang, J. Membr. Sci. 325 (2008) 801.

[60] V. Tangpasuthadol, N. Pongchaisirikul, V. P. Hoven, Carbohydrate Res. 338 (2003) 937.

[61] L. Yang, P. Chen, J. Membr. Sci. 205 (2002) 141.

[62] H.-D. Wang, R. Xi, C.H. Niu, H. Song, M. Yang, S. Liu, L.-Y. Chua, Chem. Eng. Sci. 64 (2009) 1462.

[63] S.R. Ahmed, A.B. Kelly, T.A. Barbari, J. Membr. Sci. 280 (2006) 553.

[64] M.M. Beppu, R.S. Vieira, C.G. Aimoli, C.C. Santana, J. Membr. Sci. 301 (2007) 126.

[65] B. Krajewska, React. Funct. Polym. 47 (2001) 37.

[66] C.J.M. Nova, D. Paolucci-Jeanjean, M.-P. Belleville, M.B.M. Rivallin, G. Rios, J. Membr. Sci. 321 (2008) 81.

[67] Y. Hu, M. Wang, D. Wang, X. Gao, C. Gao, J. Membr. Sci. 319 (2008) 5.

[68] C. Liu, R. Bai, J. Membr. Sci. 279 (2006) 336.

[69]C. Liu, R. Bai, J. Membr. Sci. 267 (2005) 68.

[70] C.K. Larive, S.M. Lunte, M. Zhong, M.D. Perkins, S. George, G.S. Wilson, Anal. Chem. 71 (1999) 389R.

[71] R.T. Kurnik, A.W. Yu, G.S. Blank, A.R. Burton, D. Smith, A.M. Athalye, Biotechnol. Bioeng. 45 (1995) 149.

[72] R.V. Reis, A.L. Zydney. J. Membr. Sci. 297 (2007) 16.

[73] A. Chollangi, M.M. Hossain, Chem. Eng. Process 46 (2007) 398.

[74] J. Mathew, C.T. A. Kumar, U. K. Aravind, J. Membr. Sci. 325 (2008) 625.

[75] S. Boributh, A. Chanachai, R. Jiraratananon, J. Membr. Sci. 342 (2009) 97.

[76] U. K. Aravind, J. Mathew, C.T. Aravindakumar, J. Membr. Sci. 299 (2007) 146.

[77] P. Schausberger, N. Norazman, H. Li, V. Chen, A. Fried, J. Membr. Sci. 337 (2009) 1. 
[78] D.A. Musale, A. Kumar, G. Pleizier, J. Membr. Sci. 154 (1999) 163.

[79] H. Bechhold New York: Chemical Catloge Company New York; 1926.

[80] H. Yukawa, K. Shimura, A. Suda, J. Chem. Eng. Japan 16 (1983) 305.

[81] K. Weber, W. Stahl, Chem. Eng. Technol. 26 (2003) 44.

[82] H. Yoshida, K. Kitajyo, M. Nakayama, Drying. Technol. 17(1999) 539.

[83] H. Yukawa, K. Shimura, A. Suda, A. Maniwa, J. Chem. Eng. Japan 16(1983) 246.

[84] J.W. Yu, I. Neretnieks, Chem. Eng. Sci. 51(1996) 4355.

[85] J.D. Henry, L.F. Lawler, C.H. A. Kuo, AIChE J. 23(1977) 851.

[86] A.D. Enevoldsen, E.B. Hansen, G. Jonsson, J. Membr. Sci. 299 (2007) 28.

[87] C.W. Robinson, M.H. Siegel, A. Condemine, C. Fee, T.Z. Fahidy, B.R. Glick, J. Membr. Sci. 80 (1993) 209.

[88] G. Bargeman, G.H. Koops, J. Houwing I. Breebaart H.C. Van der Horst, M. Wessling Desalination 149 (2002) 369.

[89] M. Sung, C.P. Huang, Y.H. Weng, Y.T. Lin, K.C. Li, Sep. Purif. Technol. 54(2007) 170.

[90] B.D. Fair, A.M. Jamiesson, J. Colloid Interface Sci. 73 (1980) 130.

[91] R.J. Wakeman, E.S. Tarleton, Filtr. Sep. 23 (1986) 174.

[92] C. Guizard, F. Legault, N. Idrissi, A. Larbot, C. Gavach, J. Membr. Sci. 38 (1988) 147.

[93] G.M. Rios, H. Rakatoarisoa, B.T. Fuente. J. Membr. Sci. 38 (1988) 147.

[94] E. Iritani, K.Ohashi, T. Murase J. Chem. Eng. Japan 14 (1998) 79.

[95] D. Zhou, H. Zhao, W.E. Price, G.G. Wallace. J. Membr. Sci. 98(1995) 173.

[96] H. Nakakura, A. Yamashita, M. Sambuichi, K. Osasa, J. Chem. Eng. Japan 30(1997) 1020.

[97] R.J.Wakeman, Trans I Chem. E Part C Food. Bioprod. Proc. 76 (1998) 53.

[98] S. Kimura, T. Nomura J. Membr. Sci. 7(1982) 245.

[99] V. Karthik, S D. Gupta, S. De. J. Membr. Sci. 199(2002) 29.

[100] A.K. Turkson, J.A. Mikhlin, M.E. Weber, Sep. Sci. Technol. 24 (1990) 1261.

[101] B.M.Verdegan, Sep. Sci. Technol. 21(1986) 603.

[102] C. Visvanathan R.B. Aim Sep. Sci. Technol. 24(1989) 383.

[103] S.P. Moulik, F.C. Cooper, M. Bier J. Colloid Interface Sci. 24 (1967) 427.

[104] J.M. Radovitch, N.S. Mason, R.E. Spark. Sep. Sci. Technol. 15 (1980) 1491.

[105] A. Saxena, B. P. Tripathi, V.K. Shahi, J. Colloid Interface Sci. 319 (2008) 252.

[106] K. Kordesch, G. Simader, VCH Publishers Inc., New York, 1996.

[107] A. B. Stambouli, E. Traversa, Fuel cells, Renew. Sustain. Energy Rev. 6 (2002) 297.

[108] A. B. Stambouli, E. Traversa, Renew. Sustain. Energy Rev. 6 (2002) 297.

[109] Y. Xiang, M. Yang, Z. Guo, Z. Cui, J. Membr. Sci. 337 (2009) 318.

[110] Y. Zhang, Z. Cui, C. Liu, W. Xing, J. Zhang J. Power Sources 194 (2009) 730.

[111] B. Smitha, S. Sridhar, A.A. Khan, Macromolecules, 37 (2004) 2233.

[112] Y. Wan, B. Peppley, K. A.M. Creber, V. T. Bui, E. Halliop, J. Power Sources 162 (2006) 105.

[113] H. Wu, B. Zheng, X. Zheng, J. Wang, W. Yuan, Z. Jiang, J. Power Sources 173 (2007) 842.

[114] Y. Xiong, Q. L. Liu, Q. G. Zhang, A. M. Zhu, J. Power Sources 183 (2008) 447.

[115] P. Mukoma, B.R. Jooste, H.C.M. Vosloo, J. Membr. Sci. 243 (2004) 293.

[116] M. Yamada, I. Honma, Electrochim. Acta 50 (2005) 2837.

[117] P.O. Osifo, A. Masala, J. Power Sources 195 (2010) 4915.

[118] Y. Wan, K. A.M. Creber, B. Peppley, V. Tam Bui, J. Membr. Sci. 280 (2006) 666. 
[119] J. Wang, X. Zheng, H. Wu, B. Zheng, Z. Jiang, X. Haob, B. Wang J. Power Sources 178 (2008) 9.

[120] J. Wang, Y. Zhang, H. Wu, L. Xiao, Z. Jiang, J. Power Sources 195 (2010) 2526.

[121] J.A. Seo, J. H. Koh, D. K. Roh, J. H. Kim, Solid State Ionics 180 (2009) 998.

[122] F. Goktepe, S.U. Celik, A. Bozkurt, J. Non-Crystalline Solids 354 (2008) 3637.

[123] B. Smitha, D. A. Devi, S. Sridhar, J. Hyd. Energy, 33 (2008) 4138.

[124] V.V. Binsu, R.K. Nagarale, V.K. Shahi, P.K. Ghosh, React. Funct. Polym. 66 (2006) 1619.

[125] J. Ramirez-Salgado, Electrochim. Acta 52 (2007) 3766.

[126] P. Mukoma, B.R. Jooste, H.C.M. Vosloo, J. Power Sources 136 (2004) 16.

[127] B. Smitha, S. Sridhar, A.A. Khan, Europ. Polymer J. 41 (2005) 1859.

[128] Y. Wang, D. Yang, X. Zheng, Z. Jiang, J. Li, J. Power Sources 183 (2008) 454.

[129] L.C. Cogo, M.V. Batisti, M.A. Pereira-da-Silva, O.N. Oliveira Jr, F.C. Nart, F. Huguenin, J. Power Sources 158 (2006) 16

[130] H. Wu, W. Hou, J. Wang, L. Xiao, Z. Jiang, J. Power Sources 195 (2010) 4104.

[131] Z. Cui, C. Liu, T. Lu, W. Xing, J. Power Sources 167 (2007) 94.

[132] Y. Xiong, Q.L. Liu, Q.G. Zhang, A.M. Zhu, J. Power Sources 183 (2008) 447.

[133] Z. Jiang, X. Zheng, H. Wu, J. Wang, Y. Wang, J. Power Sources 180 (2008) 143.

[134] L. Depre, M. Ingram, P.M. Poinsignon, Electrochim. Acta 45 (2000) 1377.

[135] V.V. Binsu, R.K.Nagarale, V.K. Shahi, J. Mater. Chem. 15 (2005) 4823.

[136] A. Saxena, B.P. Tripathi, V.K. Shahi, J. Phys. Chem. B 111(2007) 12454.

[137] V. Ganesan, A.Walcarius, Langmuir, 20 (2004) 3632.

[138] R. K.Nagarale, G. S.Gohil, V. K. Shahi, R. Rangarajan, Macromolecules 37(2004) 10023.

[139] M. Schuster, W.H. Meyer, G.Wenger, H.G. Herz, M. Ise, M. Schuster, K. D. Kreuer, J. Solid State Ionics 145 (2001) 85.

[140] S. Jacob, S. Cohet, C. Poinsignon, M. Popall, Electrochim. Acta 48 (2003) 2181.

[141] H.Wu, B. Zheng, X. Zheng, J. Wang, W. Yuan, Z. Jiang, J. Power Sources 173 (2007) 842.

[142] K. Soontarapa, U. Intra, Chem. Eng. Comm. 193(2006)855.

[143] C. Lau, G. Martin, S. D. Minteer, M.J. Cooney, Electroanalysis 22 (2010) 793.

[144] S. Mohanapriya, S.D. Bhat, A.K. Sahu, S. Pitchumani, P. Sridhar, A.K. Shukla, Energy Environ. Sci. 2 (2009) 1210.

[145] M.Y. Kariduraganavar, J.G. Varghese, S.K. Choudhari, R.H. Olley, Ind. Eng. Chem. Res. 48 (2009) 4002.

[146] T. Uragami, T. Katayama, T. Miyata, H. Tamura, T. Shiraiwa, A. Higuchi, Biomacromolecules 5(2004) 1567.

[147] R.Y.M. Huang, G.Y. Moon, R. Pal, J. Membr. Sci. 184 (2001) 1.

[148] R.Y.M. Huang, G.Y. Moon, R. Pal, J. Membr. Sci. 176 (2000) 223.

[149] Q. Zhao, J. Qian, Q. An, C. Gao, Z. Gui, H. Jin, J. Membr. Sci. 333 (2009) 68.

[150] X. Feng, R.Y. H. Huang, J. Membr. Sci. 116 (1996) 67.

[151] Y.M. Lee, S. Y. Nam, D. J. Woo, J. Membr. Sci. 133 (1997) 103.

[152] M.G.M. Nawawi, R.Y.M Huang, J. Membr. Sci. 124 (1997) 53.

[153] J. H. Chen, Q. L. Liu, X. H. Zhang, Q. G. Zhang, J. Membr. Sci. 292 (2007) 125.

[154] W. Won, X. Feng, D. Lawless, J. Membr. Sci. 209 (2002) 493.

[155] D.A. Devi, B. Smitha, S. Sridhar, T.M. Aminabhavi, J. Membr. Sci. 280 (2006) 45.

[156] W. Won, X. Feng, D. Lawless, Sep. Purif. Technol. 31 (2003) 129.

[157] B.-B. Li, Z.-L. Xu, F. A. Qusay, R. Li, 193 (2006) 171.

[158] V. Dubey, L. K. Pandey, C. Saxena, J. Membr. Sci. 251 (2005) 131. 
[159] A.L. Ahmad, M.G. M. Nawawi, L.K. So, J. Appl. Polymer Sci. 99, (2006) 1740

[160] K.S.V.K. Rao, M.C.S. Subha, M. Sairam, N.N. Mallikarjuna, T.M. Aminabhavi, J. Appl. Polymer Sci. 103 (2007) 1918. 


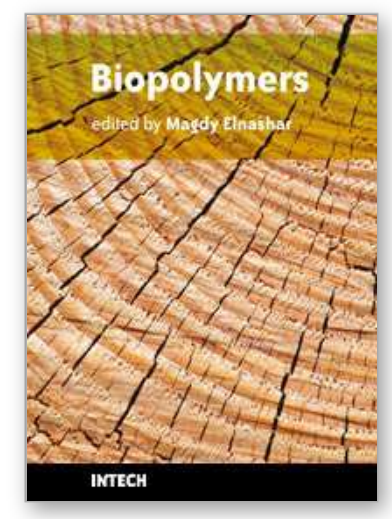

\author{
Biopolymers \\ Edited by Magdy Elnashar
}

ISBN 978-953-307-109-1

Hard cover, 612 pages

Publisher Sciyo

Published online 28, September, 2010

Published in print edition September, 2010

Biopolymers are polymers produced by living organisms. Cellulose, starch, chitin, proteins, peptides, DNA and RNA are all examples of biopolymers. This book comprehensively reviews and compiles information on biopolymers in 30 chapters. The book covers occurrence, synthesis, isolation and production, properties and applications, modification, and the relevant analysis methods to reveal the structures and properties of some biopolymers. This book will hopefully be of help to many scientists, physicians, pharmacists, engineers and other experts in a variety of disciplines, both academic and industrial. It may not only support research and development, but be suitable for teaching as well.

\title{
How to reference
}

In order to correctly reference this scholarly work, feel free to copy and paste the following:

Tina Chakrabarty, Mahendra Kumar and Vinod K. Shahi (2010). Chitosan Based Membranes for Separation, Pervaporation and Fuel Cell Applications: Recent Developments, Biopolymers, Magdy Elnashar (Ed.), ISBN: 978-953-307-109-1, InTech, Available from: http://www.intechopen.com/books/biopolymers/chitosan-basedmembranes-

\section{INTECH}

open science | open minds

\section{InTech Europe}

University Campus STeP Ri Slavka Krautzeka 83/A 51000 Rijeka, Croatia Phone: +385 (51) 770447

Fax: +385 (51) 686166 www.intechopen.com

\section{InTech China}

Unit 405, Office Block, Hotel Equatorial Shanghai No.65, Yan An Road (West), Shanghai, 200040, China 中国上海市延安西路65号上海国际贵都大饭店办公楼 405 单元 Phone: +86-21-62489820

Fax: $+86-21-62489821$ 
(C) 2010 The Author(s). Licensee IntechOpen. This chapter is distributed under the terms of the Creative Commons Attribution-NonCommercialShareAlike-3.0 License, which permits use, distribution and reproduction for non-commercial purposes, provided the original is properly cited and derivative works building on this content are distributed under the same license. 